Supporting Information for

\title{
Oxygen Functionalized Copper Nanoparticles for Solar-Driven Conversion of Carbon Dioxide to Methane
}

Mohammadreza Esmaeilirad ${ }^{1 \dagger}$, Alireza Kondori ${ }^{1 \dagger}$, Boao Song ${ }^{2}$, Andres Ruiz Belmonte ${ }^{1}$, Jialiang Wei $^{3}$, Kamil Kucuk ${ }^{4}$, Shubhada Mahesh Khanvilkar ${ }^{1}$, Erin Efimoff ${ }^{1}$, Wei Chen ${ }^{3}$, Carlo U. Segre ${ }^{4}$, Reza Shahbazian-Yassar², Mohammad Asadi ${ }^{1 *}$

${ }^{1}$ Department of Chemical and Biological Engineering, Illinois Institute of Technology, Chicago, IL 60616, USA.

${ }^{2}$ Department of Mechanical and Industrial Engineering, University of Illinois at Chicago, Chicago, IL 60607, USA.

${ }^{3}$ Department of Mechanical, Materials and Aerospace Engineering, Illinois Institute of Technology, Chicago, IL 60616, USA.

${ }^{4}$ Department of Physics \& CSRRI, Illinois Institute of Technology, Chicago, IL 60616, USA.

$\dagger$ These authors equally contributed to this work.

*Corresponding author, m.asadi@iit.edu

Table of Contents

S1- Catalyst preparation of oxygen functionalized copper (OFn-Cu)

S2- X-ray diffraction (XRD) of OFn-Cu nanoparticles

S3- X-ray photoelectron spectroscopy (XPS) of OFn-Cu nanoparticles

S4- X-ray absorption spectroscopy (XAS) of OFn-Cu nanoparticles

S4.1-Extended X-ray absorption fine structure (EXAFS)

S4.2- X-ray absorption near edge structure (XANES)

S5- Transmission electron microscopy (TEM) of OFn-Cu

S6- Three-electrode electrochemical setup

S7- Product analysis and faradaic efficiency (FE) measurements

S8- 13C labeled carbon dioxide experiment

S9- Number of active sites and turnover frequency (TOF) measurements

S10- Tafel plots of OFn-Cu (5 nm), $\mathrm{Cu}(5 \mathrm{~nm})$ and treated $\mathrm{Cu}$ foil

S11- In-situ Raman spectroscopy and stability experiments of OFn-Cu (5 nm) nanoparticles S12- Scanning electron microscopy (SEM) images of fresh and used electrodes

S13- Work function measurements-ultraviolet photoelectron spectroscopy (UPS) Method

S14- Two-compartment flow cell experiments: methods and materials

S15- Electrochemical performance of the solar-powered flow cell

S15.1- Methods and Materials

S15.2- Uncertainty analysis of the solar to fuel efficiency calculation

S15-3- Stability analysis of the solar-powered flow cell

S16- Computational methods 


\section{S1- Catalyst preparation of oxygen functionalized copper (OFn-Cu)}

Copper (II) nitrate trihydrate $\left[\mathrm{Cu}\left(\mathrm{NO}_{3}\right)_{2} .3 \mathrm{H}_{2} \mathrm{O}\right]$ (Sigma Aldrich), carbon black (Fuel Cell store) and sodium hydroxide [NaOH] (Sigma Aldrich) were used in the heterogeneous depositionprecipitation (DP) method for the synthesis of catalysts ${ }^{1-5}$. The nitrate solution of copper $(\mathrm{Cu})$ was prepared by adding $50 \mathrm{ml}$ of deionized water to $670 \mathrm{mg}$ of $\mathrm{Cu}$ salt. Then DP process was conducted for 12 hours on a magnetic hotplate at $90^{\circ} \mathrm{C}$. Metal ions were precipitated on $1.1 \mathrm{gr}$ of carbon black by adding $40 \mathrm{ml}$ of $6 \mathrm{wt}$. $\% \mathrm{NaOH}$ solution in specific time intervals to obtain different sizes of Cu nanoparticles with 16 wt.\% metal loading deposited on the carbon black. The solution containing the so-called $\mathrm{Cu}$ nanoparticles were then washed with deionized water, filtered and dried in a vacuum oven at $110^{\circ} \mathrm{C}$ for overnight. The dried powders were ground using a mortar and pestle and subsequently functionalized in a tubular furnace using a mixed oxygen/argon $\left(\mathrm{O}_{2} / \mathrm{Ar}\right)$ flow with the volume ratio of $\mathrm{O}_{2}: \mathrm{Ar}-1: 9$ under a pressure of 100 torr for 4 hours at 500 ${ }^{\circ} \mathrm{C}$. The obtained oxygen functionalized copper (OFn-Cu) nanoparticles are denoted by the average particle sizes. For instance, the catalyst with an average particle size of $5 \mathrm{~nm}$ is named OFn-Cu (5 nm). In addition, Cu $5 \mathrm{~nm}$ nanoparticles deposited on carbon black were synthesized using the same DP method. However, instead of $\mathrm{O}_{2} / \mathrm{Ar}$ gas mixture, a mixed flow of argon/hydrogen $\left(\mathrm{Ar} / \mathrm{H}_{2}\right)$ flow with 8 percent concentration of $\mathrm{H}_{2}$ was used in the tubular furnace for the thermal sintering step. All the samples for any characterization were transferred and stored in an Ar filled glovebox with oxygen and humidity levels less than $1 \mathrm{ppm}$ to preserve the samples from any possible oxidation/contamination. Moreover, a mobile Ar-filled glovebox (Sigma Aldrich) was also used to transfer the samples for all characterizations.

The treated $\mathrm{Cu}$ foil catalyst was also prepared using a $25-\mu \mathrm{m}$-thick Cu foil (Alfa-Aesar). To remove all impurities from the surface of the catalyst, the $\mathrm{Cu}$ foil was triple-washed with dilute sulfuric acid $\left(\mathrm{H}_{2} \mathrm{SO}_{4}, 0.05 \mathrm{M}\right.$, Sigma Aldrich), acetone (Sigma Aldrich) and methanol (Sigma Aldrich) were used. At first, dilute sulfuric acid, which has been demonstrated to remove undesired 
inorganic impurities, was introduced for 30 min. After rinsing with DI water, the Cu foil was dipped in acetone for 15 minutes to remove organic impurities, followed by rinsing in methanol and DI water. Then the treated $\mathrm{Cu}$ foil was annealed in a tubular furnace using Ar gas under a pressure of 100 torr.

\section{S2- X-ray diffraction (XRD) of OFn-Cu nanoparticles}

X-ray diffraction (XRD) patterns were collected by a Bruker D2 PHASER diffractometer in Bragg-Brentano geometry employing Ni filtered $\mathrm{Cu}$ Ka radiation. Patterns were obtained from 30 to $100^{\circ} 2 \theta$ degree using a LynxEye linear position sensitive detector. A step width of $0.2^{\circ} 2 \theta$ and a counting time of $10 \mathrm{~S} / \mathrm{step}$ were used. All other parameters were chosen to enhance the signal to noise in diffractograms. The XRD patterns of 1,5 and $15 \mathrm{~nm}$ OFn-Cu nanoparticles, $\mathrm{Cu}(5 \mathrm{~nm})$ and treated $\mathrm{Cu}$ foil are shown in main text Figure 1a (main text) and Figure S1.
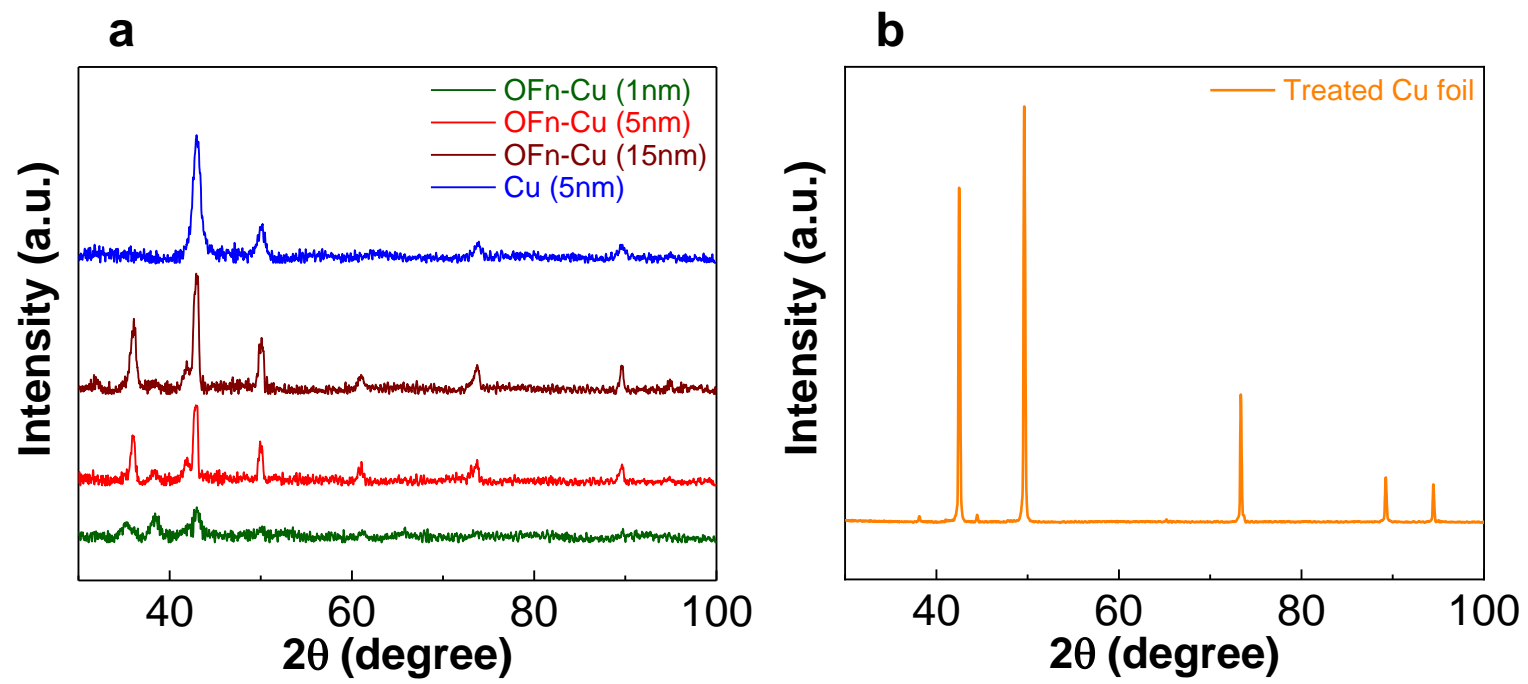

Figure S1. X-ray diffraction (XRD) patterns of catalysts. (a) 1, 5 and $15 \mathrm{~nm}$ OFn-Cu and $\mathrm{Cu}$ (5 nm). (b) Treated Cu foil

The size of crystallites for synthesized OFn-Cu and $\mathrm{Cu}$ nanoparticles were calculated using Scherrer equation as shown in Equation S1.

$$
D_{h k l}=\frac{K \lambda}{\left(\beta_{h k l} \cos \theta\right)}, \quad \text { (Equation S1) }
$$

Where $D_{h k l}$ is the crystallite size in the direction perpendicular to the lattice planes, hkl are the Miller indices of the planes being analyzed, $\mathrm{K}$ is a numerical factor frequently referred to as the 
crystallite-shape factor, $\lambda$ is the wavelength of the X-rays (X-ray tube: $\mathrm{Cu}, \lambda=0.154 \mathrm{~nm}), \beta_{h k l}$ is the width (full-width at half-maximum) of the X-ray diffraction peak in radians and $\theta$ is the Bragg angle in radians. The summary of the average crystallite sizes of synthesized nanoparticles are shown in Table S1.

Table S1: Average crystallite size of OFn-Cu and Cu nanoparticles

\begin{tabular}{cccc}
\hline Sample & $\begin{array}{c}\text { Minimum Crystallite } \\
\text { Size }(\mathrm{nm})\end{array}$ & $\begin{array}{c}\text { Maximum Crystallite } \\
\text { Size }(\mathrm{nm})\end{array}$ & $\begin{array}{c}\text { Average crystallite } \\
\text { Size }(\mathrm{nm})\end{array}$ \\
\hline OFn-Cu $(1 \mathrm{~nm})$ & 0.8 & 2.3 & 1.4 \\
OFn-Cu $(5 \mathrm{~nm})$ & 4.2 & 8.4 & 5.7 \\
OFn-Cu $(15 \mathrm{~nm})$ & 13.3 & 15.6 & 14.3 \\
$\mathrm{Cu}(5 \mathrm{~nm})$ & 2 & 7.1 & 5.2 \\
\hline
\end{tabular}

\section{S3- X-ray photoelectron spectroscopy (XPS) of OFn-Cu nanoparticles}

X-ray photoelectron spectroscopy (XPS) of OFn-Cu $(5 \mathrm{~nm})$ was obtained using a ThermoScientific ESCALAB 250Xi instrument equipped with an electron flood and scanning ion gun where the pressure of the analysis chamber was less than $2 \times 10^{-9}$ Torr (Figure 1b, main text and Figure S2). The XPS instrument was calibrated prior to the experiments with binding energies all referenced to the $\mathrm{Au} 4 \mathrm{f}_{7 / 2}$ at $83.96 \mathrm{eV}$ and $\mathrm{Ag} 3 \mathrm{~d}_{5 / 2}$ at $368.27 \mathrm{eV}$. All samples were irradiated by a monochromatic Al- $\mathrm{K}_{\alpha} \mathrm{X}$-ray source. All scans were acquired with a pass energy of $20 \mathrm{eV}, 0.05$ eV step size and dwell time of $200 \mathrm{mS}$ using a charge neutralization system (an ion flood gun). The data processing was performed using the Avantage software such that each spectrum was calibrated against the binding energy (BE) for adventitious carbon peak detected as a sharpintensity peak in the $\mathrm{C}$ 1s region $(284.8 \mathrm{eV}) .{ }^{6-8}$ All the XPS measurements including peak normalizations, binding energies and atomic compositions are based on C 1s C-C bond at 284.8 eV. For the curve-fitting, a Shirley background was used to consider the inelastic scattering. All the XPS measurements for atomic percentage ratios are based on the normalized peak intensities obtained by Avantage software in which Equation $\mathrm{S} 2$ is used to analyze the compositional ratio:

$$
C_{i}=\frac{A_{i} / S_{i}}{\sum_{i} A_{i} / S_{i}} \quad \text { Equation } \mathrm{S} 2
$$


Where $A_{i}$ stands for the area of the peak after curve-fitting and the $S_{i}$ is the sensitivity factor included in the Scofield database of the Avantage software. The values of $S_{i}$ for the elemental $\mathrm{S}_{i}(\mathrm{Cu})$ is 8.66 and for the oxide species are $\mathrm{S}_{\mathrm{i}}(\mathrm{CuO})=\mathrm{S}_{\mathrm{i}}\left(\mathrm{Cu}_{2} \mathrm{O}\right)=25.39 .{ }^{9-11}$

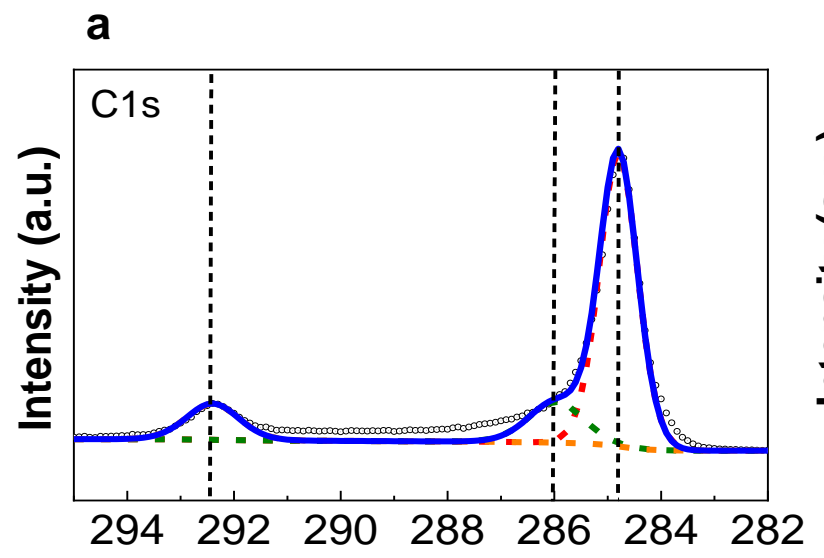

Binding Energy (eV) b

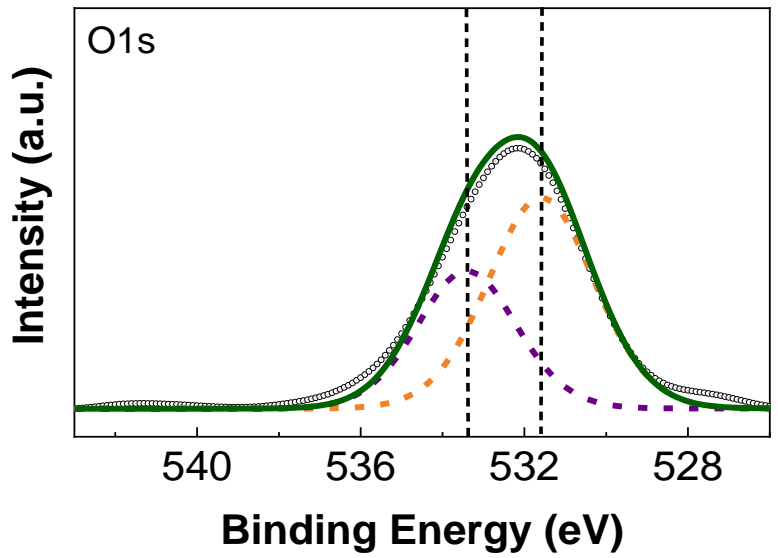

Figure S2. X-ray photoelectron spectra results of OFn-Cu (5 nm). (a) C 1s. (b) O $1 \mathrm{~s}$.

The XPS depth profile of the fresh OFn-Cu $(5 \mathrm{~nm})$ nanoparticles was obtained by combining four cycles of Ar etching followed by XPS measurements from the surface. The Ar gun was calibrated before performing experiment to have the actual depth size of $5 \AA$ at each cycle and total etched depth of $20 \AA$. The set of XPS spectra corresponding to the Cu $2 p$ peaks from a depth profile are depicted in Figure S3. The results indicate that the surface layer of the synthesized nanoparticles is dominated by $\mathrm{CuO}$ and separated from the underneath elemental $\mathrm{Cu}$ by a $\mathrm{Cu}_{2} \mathrm{O}$ sublayer. As shown in Figure S3b, the surface of the fresh sample (not etched) is mostly composed of $\mathrm{CuO}\left(90 \%\right.$ weight percentage) and a partial amount of $\mathrm{Cu}_{2} \mathrm{O}$. Additionally, as indicated in Figure S3b, the weight percentage of the $\mathrm{CuO}$ decreases in the sublayers, lowered to $13.8 \%$ after the argon etching the surface for $2 \mathrm{~nm}$ where the weight percentage of $\mathrm{Cu}_{2} \mathrm{O}$ and elemental $\mathrm{Cu}$ are $19.6 \%$ and $66.5 \%$, respectively. It is worth mentioning that due to the penetration depth of the X-ray gun, 7-8 nm, the entirety of the OFn-Cu $(1 \mathrm{~nm})$ and $(5 \mathrm{~nm})$ nanoparticles emit photoelectrons that results in complexity in interpreting the precise atomic percentages. However, our HRTEM experiments on the OFn-Cu $(5 \mathrm{~nm})$ nanoparticles indicates a d-spacing of $0.25 \mathrm{~nm}$ 
on the outer layer of nanoparticle, confirming a dominant $\mathrm{CuO}$ phase on the surface. Therefore, we believe that the partial amount of Cu2O (10.25\%) observed prior to the Ar-etching on the OFn$\mathrm{Cu}(5 \mathrm{~nm})$ is due to penetration depth of the X-ray gun $(8 \mathrm{~nm})$.
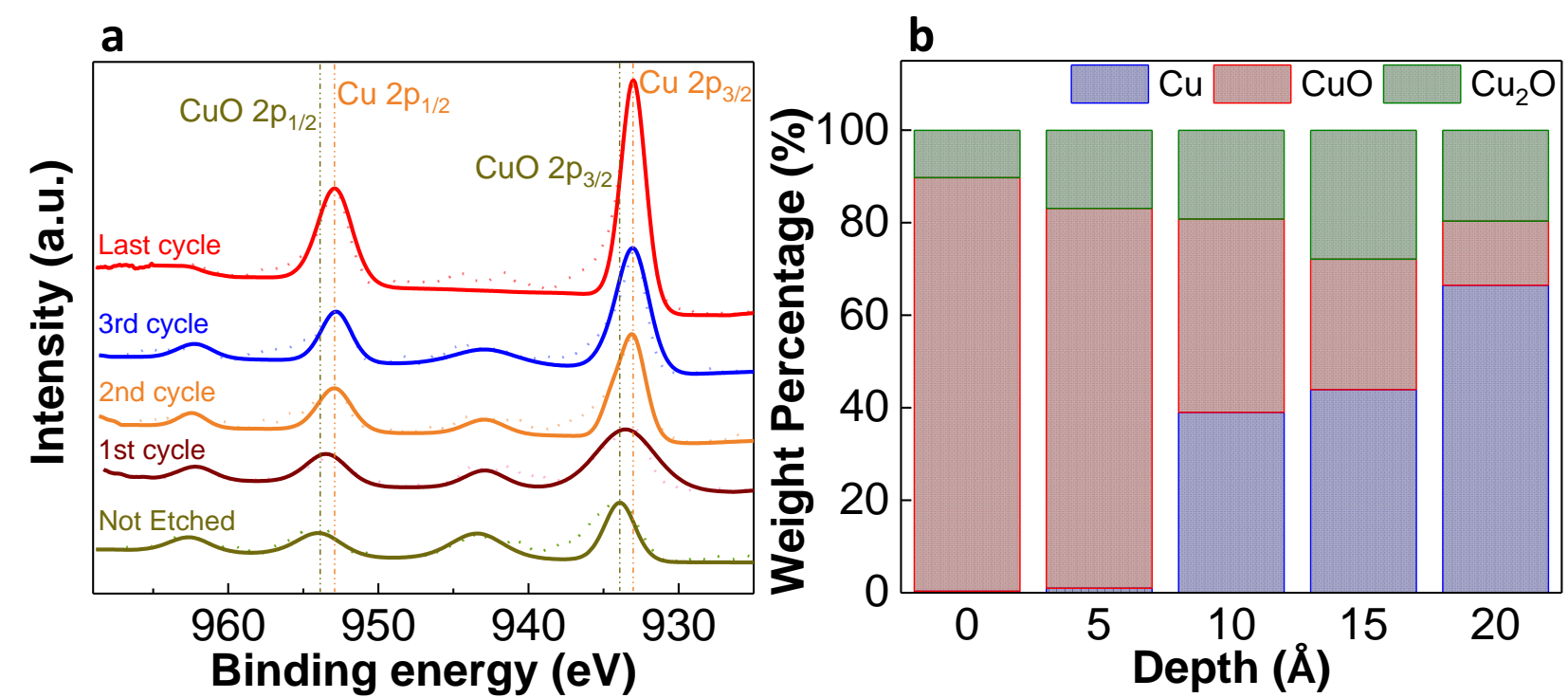

Figure S3. (a) The set of $\mathrm{Cu}$ spectra for OFn-Cu (5 nm) measured during a depth profiling experiment. (b) weight percentage of Cu compositions for OFn-Cu $(5 \mathrm{~nm})$ at different etch cycles.

It is worth noting that the accuracy of the chemical oxidation states and elemental percentages highly depend on the binding energy (BE) referencing method. To this end, the $\mathrm{C}-\mathrm{C}$ bond of adventitious carbon in the C 1s spectrum is widely used. However, in samples where different types of $C$ bonds are present, this method can result in unreliable analysis, calling the need for other referencing techniques, i.e. internal BE referencing methods for gold (Au) and Silver (Ag) containing samples. ${ }^{19-21}$ Other techniques such as synthesizing thin films $(<5 \mathrm{~nm})$ of samples on Au or Ag substrate can also be used for reliable interpretation of the XPS spectra.

We also performed depth-profile measurements on the OFn-Cu (5 nm) nanoparticles considering its $\mathrm{Cu}$ LMM peak and compared them with $\mathrm{Cu}$ LMM peak in standard $\mathrm{CuO}, \mathrm{Cu}_{2} \mathrm{O}$ and Cu samples. To measure $\mathrm{Cu}$ LMM peak of the OFn-Cu nanoparticles, the samples were transferred to the XPS loading chamber using a mobile Ar-filled glovebox (Sigma Aldrich) to avoid any possible oxidation/contamination. All XPS spectra were recorded at a pass energy of $20 \mathrm{eV}$, 
dwell time of $100 \mathrm{mS}$, step size of $0.05 \mathrm{eV}$ and 5 scans using the standard lens mode. The XPS spectra were calibrated with reference to the $\mathrm{C} 1 \mathrm{~s}$ binding energy at $284.8 \mathrm{eV}$ corresponding to the $\mathrm{C}-\mathrm{C}$ bond.

Figure S4 shows the Cu LMM XPS result of the OFn-Cu (5 nm) nanoparticles at $569.0 \pm 0.05$ eV. The reference XPS spectra of $\mathrm{CuO}\left(\mathrm{Cu}^{2+}\right), \mathrm{Cu}_{2} \mathrm{O}\left(\mathrm{Cu}^{1+}\right)$, and $\mathrm{Cu}\left(\mathrm{Cu}^{0}\right)$, shown in this figure, are extracted from references. The $\mathrm{Cu} L M M$ peaks of $\mathrm{CuO}\left(\mathrm{Cu}^{2+}\right), \mathrm{Cu}_{2} \mathrm{O}\left(\mathrm{Cu}^{1+}\right)$, and $\mathrm{Cu}\left(\mathrm{Cu}^{0}\right)$ are at 568.9, 570.1, and 568.3 eV, respectively. Comparing the Cu LMM peak in the XPS spectra of the OFn-Cu (5 nm) nanoparticles and reference $\mathrm{CuO}$ indicates a small shift in the Cu LMM peak (about $0.1 \mathrm{eV})$, suggesting that the surface oxidation state of the OFn-Cu $(5 \mathrm{~nm})$ nanoparticles is mainly dominated by $\mathrm{CuO}$ (Figure S4).

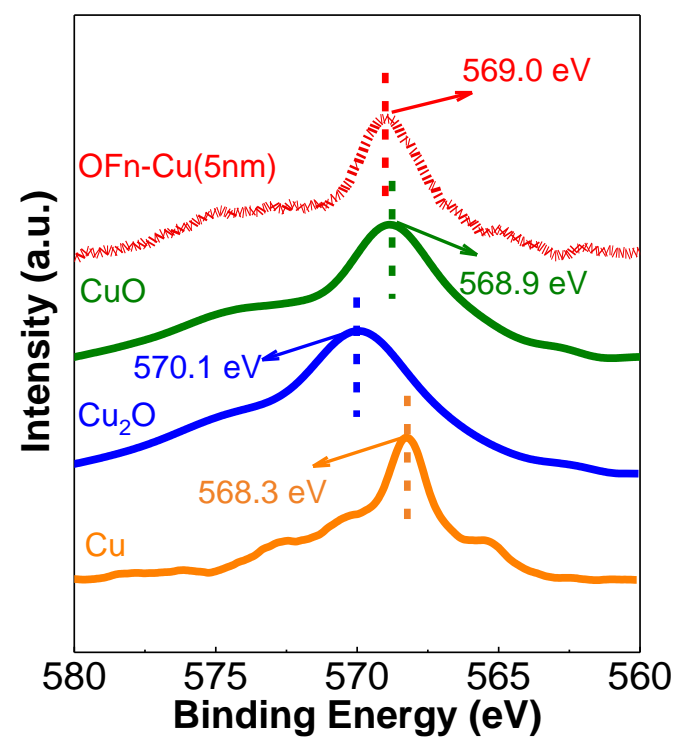

Figure S4. Cu LMM Auger peak of OFn-Cu $(5 \mathrm{~nm})$ compared with $\mathrm{Cu}, \mathrm{Cu}_{2} \mathrm{O}$, and $\mathrm{CuO}$ reference XPS spectra, extracted from references

To calculate the surface composition of the OFn-Cu $(5 \mathrm{~nm})$ nanoparticles, we analyzed the OFn$\mathrm{Cu}(5 \mathrm{~nm})$ XPS spectrum by considering the reference $\mathrm{Cu}$ LMM peaks of $\mathrm{CuO}, \mathrm{Cu}_{2} \mathrm{O}$ and $\mathrm{Cu}$ using Avantage software. Our measurements indicate relative atomic percentages of $90.5 \%$, $8.74 \%$ and $0.76 \%$ for $\mathrm{CuO}, \mathrm{Cu}_{2} \mathrm{O}$ and $\mathrm{Cu}$, respectively, that are fairly consistent with our measurements using Cu 2p XPS spectra. 


\section{S4- X-ray absorption spectroscopy (XAS) of OFn-Cu nanoparticles}

EXAFS spectra were taken on the nominal $15 \mathrm{~nm}, 5 \mathrm{~nm}$, and $1 \mathrm{~nm}$ samples in transmission at the Materials Research Collaborative Access Team (Sector 10) bending magnet beamline at the Advanced Photon Source of Argonne National Laboratory ${ }^{22}$. A small amount of sample was ground in a mortar with boron nitride and PVDF and then pressed into a $7 \mathrm{~mm}$ pellet. Three separate batches of OFn-Cu (15 nm, $5 \mathrm{~nm}, 1 \mathrm{~nm})$ samples were measured at the Cu K-edge. All data sets were analyzed independently for consistency using Athena and Artemis from the IFEFFIT suite ${ }^{23,24}$.

\section{S4.1-Extended X-ray absorption fine structure (EXAFS)}

The data were normalized and background subtracted to obtain the $\chi(k)$ then weighted by $\mathrm{k}^{3}$. The Fourier Transform was taken on the data from 2-12 $\AA^{-1}$ and the fits were performed in Rspace over the range of 1.0-2.8 $\AA$ using a Cu-O path and a Cu-Cu path. The results of the EXAFS fits for the OFn-Cu catalysts of nominal size 15, 5, and $1 \mathrm{~nm}$ are presented in Table S2 and shown in Figure S4. The $\mathrm{Cu}-\mathrm{O}$ bond length in all the samples is intermediate between the $\mathrm{Cu}_{2} \mathrm{O}$ bond distance $(1.85 \AA)$ and the $\mathrm{CuO}$ bond distance $(1.95 \AA)$ and its value is roughly indicative of the relative amounts of $\mathrm{Cu}_{2} \mathrm{O}$ and $\mathrm{CuO}$ present. The $\mathrm{Cu}-\mathrm{Cu}$ bond distance is substantially constant over the whole series of samples confirming the presence of a Cu metal core in the nanoparticles.

Table S2. Results of the EXAFS fits for OFn-Cu samples

\begin{tabular}{ccccccc}
\hline Size & $N_{0}$ & $R(\mathrm{Cu}-\mathrm{O}))$ & $\sigma^{2}(\mathrm{Cu}-\mathrm{O})$ & $\mathrm{N}_{\mathrm{Cu}}$ & $\mathrm{R}(\mathrm{Cu}-\mathrm{Cu})$ & $\sigma^{2}(\mathrm{Cu}-\mathrm{Cu})$ \\
\hline $15 \mathrm{~nm}$ & $0.9 \pm 0.4$ & $1.85 \pm 0.02$ & $0.009 \pm 0.001$ & $6.3 \pm 0.9$ & $2.56 \pm 0.01$ & $0.009 \pm 0.001$ \\
$5 \mathrm{~nm}^{*}$ & $1.8 \pm 0.5$ & $1.91 \pm 0.01$ & $0.005 \pm 0.003$ & $4.0 \pm 0.8$ & $2.56 \pm 0.01$ & $0.009 \pm 0.001$ \\
$1 \mathrm{~nm}^{*}$ & $3.3 \pm 0.6$ & $1.93 \pm 0.01$ & $0.006 \pm 0.003$ & $3.3 \pm 0.7$ & $2.56 \pm 0.01$ & $0.007 \pm 0.001$ \\
\hline
\end{tabular}

*Merged data from two samples 

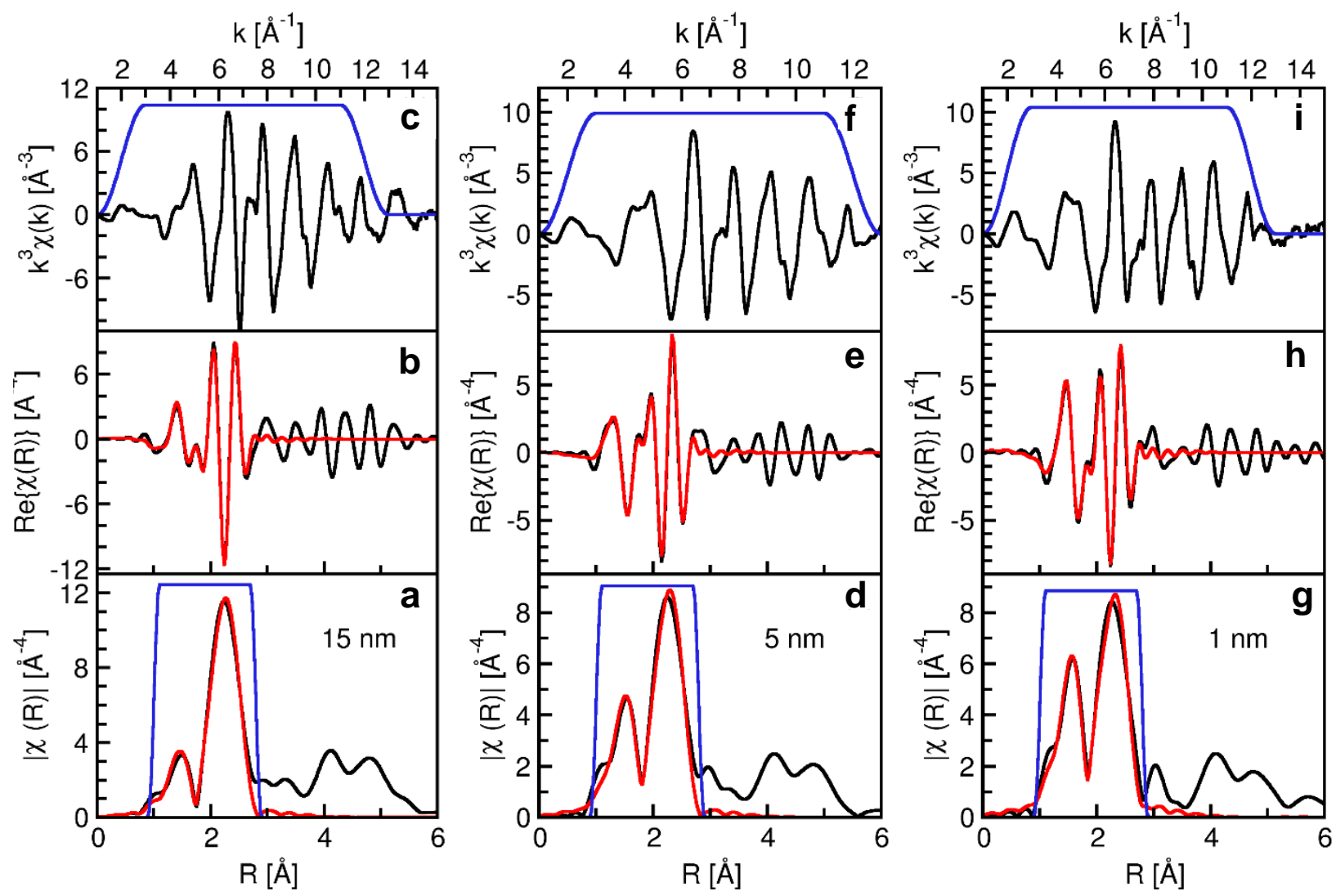

Figure S5. EXAFS fits of OFn-Cu nanoparticles with nominal sizes of: (a-c) $15 \mathrm{~nm}$, (d-f) $5 \mathrm{~nm}$, and (g-i) 1 $\mathrm{nm}$. The data is in black, the fits in red and the Fourier Transform and fitting windows in blue. The bottom panel presents the magnitude of the EXAFS Fourier Transform weighted by $\mathrm{k}^{3}$, the middle panel shows the real part of the EXAFS Fourier Transform weighted by $\mathrm{k}^{3}$, and the top panel shows the EXAFS weighted by $k^{3}$.

Figure S6 shows Fourier Transform of EXAFS spectra of series of OFn-Cu samples compared with the standard EXAFS spectrum of $\mathrm{Cu}$.

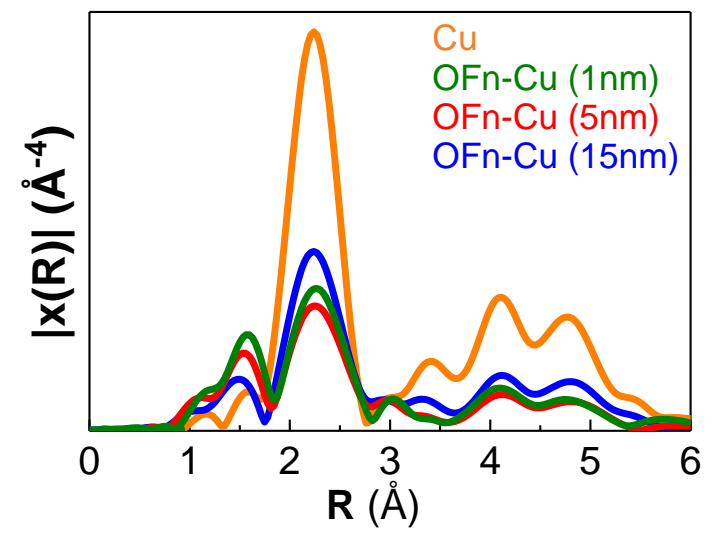

Figure S6. Fourier Transform of EXAFS spectra of series of OFn-Cu samples compared with standard EXAFS spectrum of $\mathrm{Cu}$ 


\section{S4.2- X-ray absorption near edge structure (XANES)}

Figure S7 shows the Cu K-edge XANES spectra of the OFn-Cu nanoparticles and three reference materials which appear in the XRD patterns. The reference materials have distinct features which also appear in the catalyst nanoparticles. In order to estimate the amount of $\mathrm{Cu}$, $\mathrm{Cu}_{2} \mathrm{O}$, and $\mathrm{CuO}$ in the catalyst materials, a least square fitting of the derivative of the XANES was performed using the three reference spectra. Table S3 shows the results of the fits which are representative of the amount of each phase in each catalyst sample.

The relative amounts of $\mathrm{Cu}_{2} \mathrm{O}$ and $\mathrm{CuO}$ in the nanoparticles are consistent with the values obtained for the $\mathrm{Cu}-\mathrm{O}$ bond lengths and indicate that the smallest particles have the most $\mathrm{CuO}$. Using the fractions of $\mathrm{Cu}$ metal in each sample permits an estimate of the size of the Cu cores by taking the number of $\mathrm{Cu}-\mathrm{Cu}$ bonds measured from the EXAFS fits and dividing by the atomic fraction of $\mathrm{Cu}$ metal in the sample. A value of $\mathrm{N}_{\mathrm{Cu}=12}$ indicates bulk for an FCC structure which is found at a nanoparticle size of roughly $10 \mathrm{~nm}$. Smaller values of $\mathrm{N}_{\mathrm{Cu}}$ can be used to estimate the nanoparticle size assuming a spherical shape. $\mathrm{D}_{\mathrm{cu}}$ values for the 5 and $1 \mathrm{~nm}$ shown in Table S3 are consistent with the nominal particle sizes.

Table S3. Results of least squares fits to the XANES data for OFn-Cu catalysts and estimated Cu core sizes

\begin{tabular}{|c|c|c|c|c|c|}
\hline Size & $\mathrm{Cu} \%$ & $\mathrm{Cu}_{2} \mathrm{O} \%$ & $\mathrm{CuO} \%$ & $\mathrm{~N}_{\mathrm{Cu}}$ (cores) & $\mathrm{D}_{\mathrm{Cu}}(\mathrm{nm})$ \\
\hline $15 \mathrm{~nm}$ & $52 \pm 1$ & $37 \pm 1$ & $37 \pm 2$ & $\sim 12.1$ & $>10$ \\
\hline $5 \mathrm{~nm}^{*}$ & $37 \pm 2$ & $27 \pm 2$ & $36 \pm 3$ & $\sim 11.0$ & $\sim 4.0$ \\
\hline $1 \mathrm{~nm}^{*}$ & $38 \pm 3$ & $6 \pm 3$ & $56 \pm 4$ & $\sim 8.9$ & $\sim 1.3$ \\
\hline
\end{tabular}




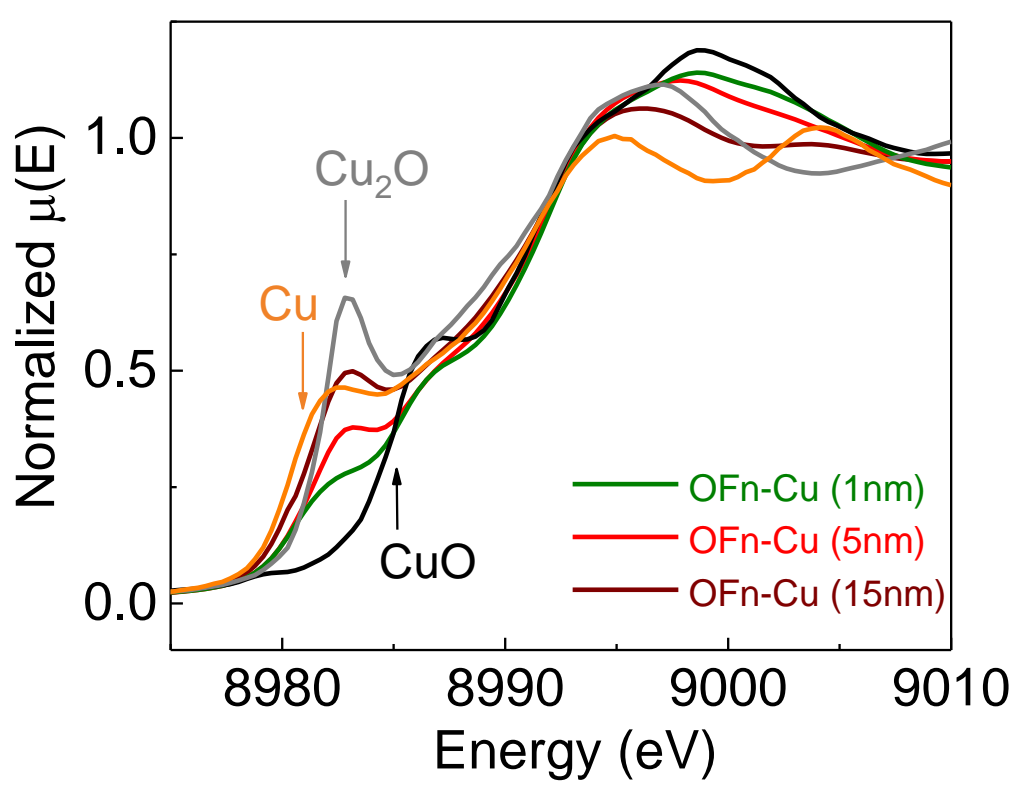

Figure S7. XANES spectra of of OFn-Cu nanoparticles with nominal sizes of 15,5 , and $1 \mathrm{~nm}$ and $\mathrm{Cu}, \mathrm{Cu}_{2} \mathrm{O}$, and $\mathrm{CuO}$ standards. The arrows indicate the characteristic features of each standard.

\section{S5- Transmission electron microscopy (TEM) of OFn-Cu}

OFn-Cu $(5 \mathrm{~nm})$ catalyst was characterized by drop casting dispersion solution on copper grid to investigate the particle size distribution and morphology of the prepared sample using a spherical aberration corrected JEOL JEM-ARM 200CF STEM with a cold field emission gun operating at $200 \mathrm{kV}$, with 22 mrad convergence angle. Images were taken using an Orius CCD camera with $512 \times 512$ scanning resolution. Figure S8 shows the low-angle annular dark field HAADF images of OFn-Cu $(5 \mathrm{~nm})$ nanoparticles. Three exemplary OFn-Cu $(5 \mathrm{~nm})$ nanoparticles were measured with line intensity profile shown in Figure S8c indicating the $\sim 5 \mathrm{~nm}$ size range.
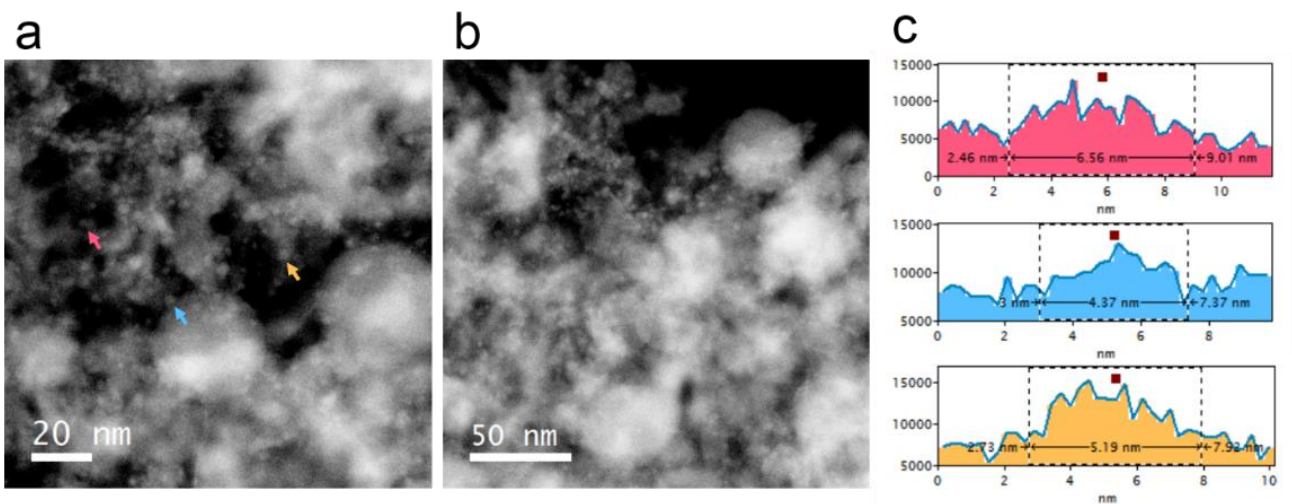

Figure S8. (a-b) LAADF images of OFn-Cu $(5 \mathrm{~nm})$ nanoparticles on carbon black. (c) Line profile of three exemplary OFn-Cu nanoparticles marked in a showing particle size around $5 \mathrm{~nm}$. 
Figures S9a and f show the low-angle annular dark field (LAADF) images of the well-dispersed OFn-Cu (5 nm) nanoparticles, confirming spherical shape and uniform size distribution for OFnCu nanoparticle synthesized on the carbon black support. The electron energy loss spectrum (EELS) mapping shown in Figures S9a-f was acquired from the area in Figure 1e, showing the elemental distribution of carbon $(\mathrm{C}$, blue), oxygen $(\mathrm{O}$, red), and $\mathrm{Cu}$ (yellow) that are extracted from $\mathrm{C} \mathrm{K}, \mathrm{O} \mathrm{K}$, and $\mathrm{Cu}$ L-edge signals. Figure 1i shows the overlaid EELS mapping of the area shown in Figure 1e.
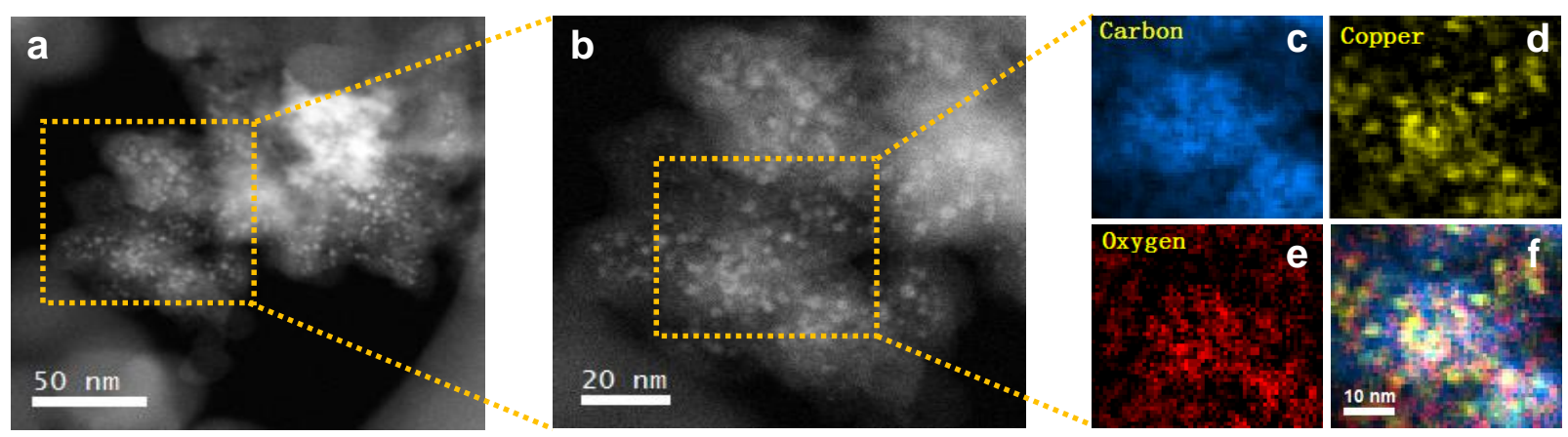

Figure S9. (a-b) Low angle annular dark field (LAADF) image of OFn-Cu (5 nm) on carbon black substrate (scale bars are $50 \mathrm{~nm}$ and $20 \mathrm{~nm}$, respectively). Electron energy loss spectroscopy (EELS) mapping of the area shown in Figure 1e, showing (c) C K-edge, (d) O K-edge, (e) Cu L-edge, and (f) overlaid EELS mapping.

Figure S10a shows STEM image of OFn-Cu (15nm). The nanoparticles are uniformly distributed on the carbon substrate. Three exemplary OFn-Cu (15nm) nanoparticles are measured and shown in Figure S10b as line intensity indicating the size range in $\sim 15 \mathrm{~nm}$.
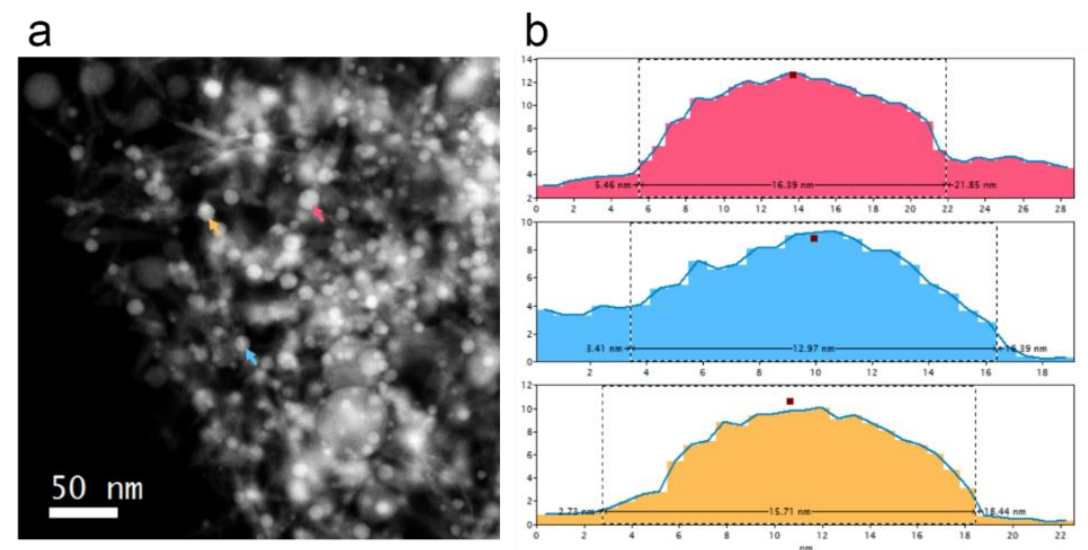

Figure 10. (a) LAADF image of OFn-Cu (15 nm) sample. (b) Line profile of three exemplary Cu nanoparticles marked in a showing particle size around $15 \mathrm{~nm}$. 


\section{S6- Three-electrode electrochemical setup}

For all electrochemical experiments, a custom-designed two-compartment three-electrode electrochemical cell was used to perform carbon dioxide $\left(\mathrm{CO}_{2}\right)$ reduction reaction. Figure $\mathrm{S} 11$ indicates a schematic of the electrochemical cell. The synthesized OFn-Cu (1 to $15 \mathrm{~nm}$ ) and Cu $(5 \mathrm{~nm})$ catalysts were coated on a customized glassy carbon (GC) electrode, used as the working electrode, by drop casting method. ${ }^{25}$ The catalyst loading on the electrode was precisely controlled to be $0.1 \mathrm{mg}$ on the glassy carbon electrode with the surface area of $1 \mathrm{~cm}^{2}$.

We performed cyclic voltammetry (CV) experiments to evaluate the catalytic performance of each synthesized catalyst. All experiments were performed under identical electrochemical conditions in the cell with a $1 \mathrm{M} \mathrm{KHCO}_{3}$ electrolyte saturated with $\mathrm{CO}_{2}$ (UHP 99.99\%, Airgas). ${ }^{25}$ Platinum (Pt) gauze 52 mesh (Alfa Aesar) and $\mathrm{Ag} / \mathrm{AgCl}$ (BASi) were used as counter and reference electrodes, respectively. The cathode and anode parts of the cell were separated through an ion exchange membrane to eliminate the effect of product oxidation at the anode surface.

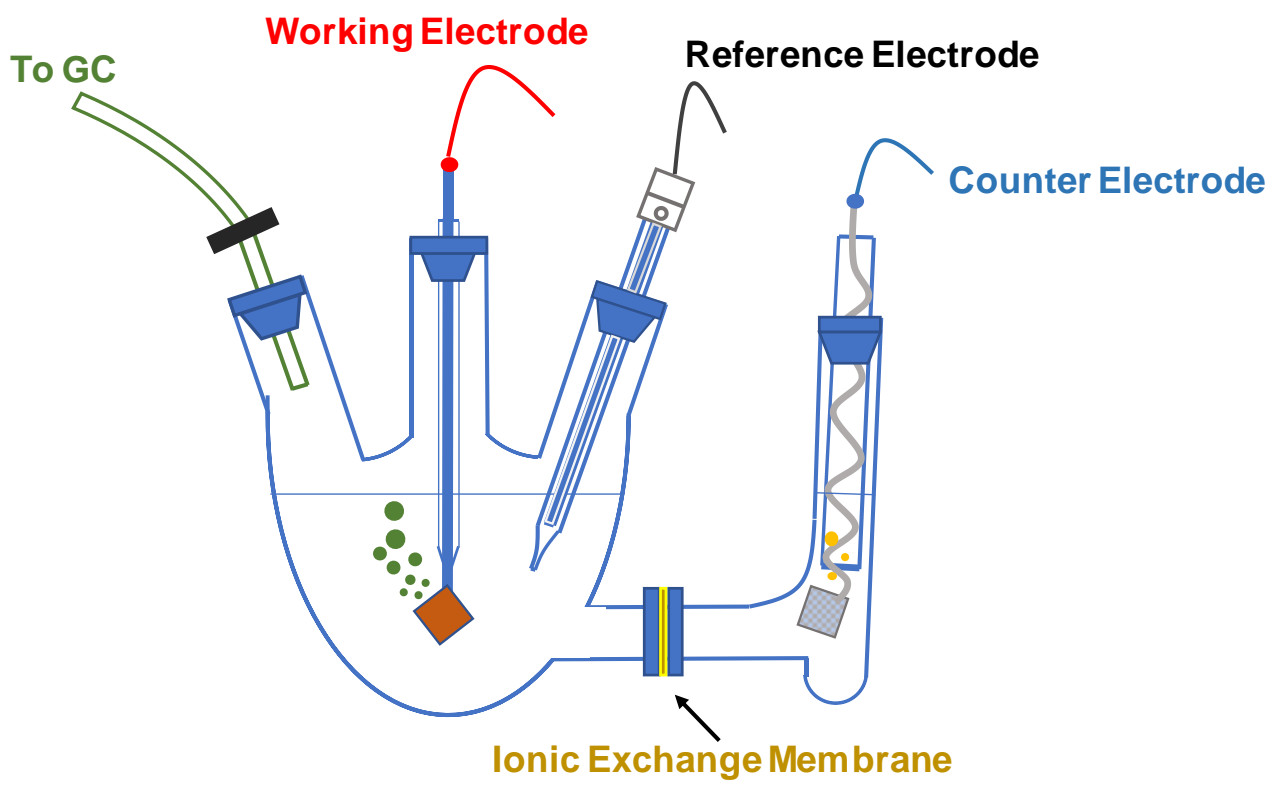

Figure S11. A schematic of customized two-compartment three-electrode electrochemical cell. 
The $\mathrm{pH}$ of the electrolyte was measured before and after the experiments using a Thermo Scientific Orion A111 pH meter. The results indicate that $\mathrm{pH}$ value remained almost constant (about 8.0) before and after $\mathrm{CO}_{2}$ reduction reaction. The cell was connected to the potentiostat (SP 150 Biologic) for the electrolysis experiments. As shown in Figure S12, the LSV curves (j-V) were obtained by sweeping the potential between +0.3 and $-1.25 \mathrm{~V} v \mathrm{RHE}$ with scan rate of 20 $\mathrm{mV} / \mathrm{s}$. All potentials were converted to the reversible hydrogen electrode (RHE) using Equation $\mathrm{S} 3$ as follow where $\mathrm{E}_{\mathrm{Ag} / \mathrm{AgCl}-\mathrm{RHE}}^{0}=0.1976$ and $\mathrm{pH}$ of solution $=8$ :

Potential in $R H E=$ Applied potential vs $\mathrm{Ag} / \mathrm{AgCl}+0.197 \mathrm{~V}+0.0592 \times p H($ Equation S3)

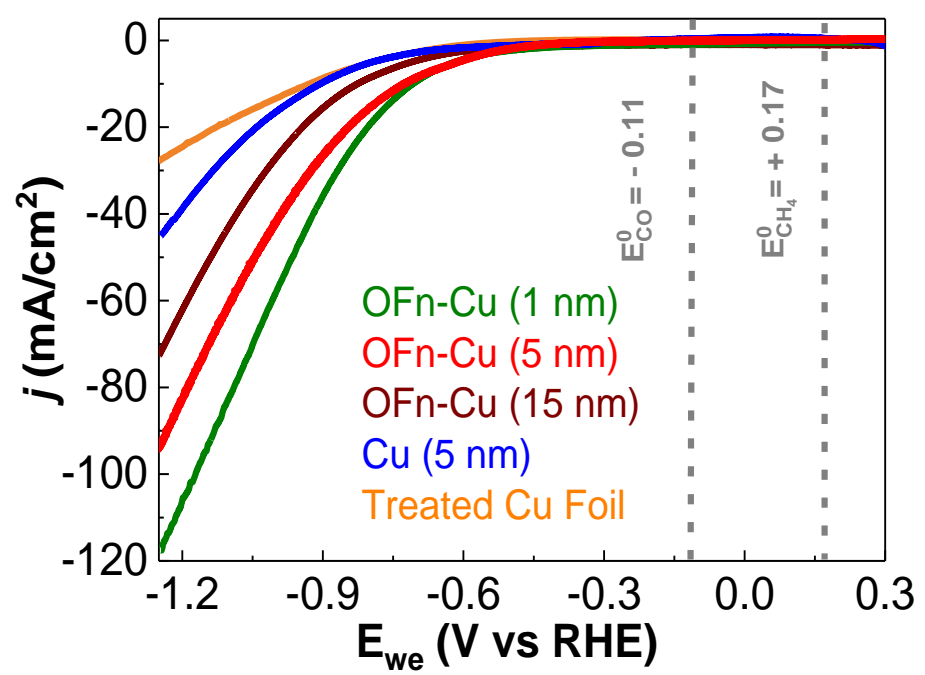

Figure S12. Linear sweep voltammetry (LSV) results for three different batches of different catalysts with respect to $\mathrm{RHE}$ at a scan rate of $20 \mathrm{mV} / \mathrm{s}$. The recorded potentials are measured using $\mathrm{Ag} / \mathrm{AgCl}$ reference electrode and then converted to RHE.

\section{S7- Product analysis and faradaic efficiency (FE) measurements}

The selectivity of the catalysts was evaluated and compared by analyzing them in a twocompartment three electrodes electrochemical setup coupled with gas chromatography. We performed all experiments under standard conditions of saturated $1 \mathrm{M} \mathrm{KHCO}_{3}$ electrolyte saturated with $\mathrm{CO}_{2}$. A platinum (Pt) gauze 52 mesh (Alfa Aesar) was used as a counter electrode. The synthesized catalysts were coated on glassy carbon electrodes with $1 \mathrm{~cm}^{2}$ geometric surface area by drop casting method and were employed as the working electrode in the electrochemical 
cell. Then, chronoamperometry $(C A)$ experiments were performed for the specific amount of time at different potentials. To analyze the products of the electrochemical experiment, $1 \mathrm{ml}$ samples were taken out from the dead volume of the cell using a lock-in syringe (Hamilton) and injected into the gas chromatography system (SRI 8610C Multiple Gas Analyzer) at identical conditions.

The GC system used to identify the sample was consisted of a sampling loop equipped with a flame ionization detector (FID) and a thermal conductivity detector (TCD). Ultra-high purity helium and nitrogen gasses (UHP 99.99\%, Airgas) were used as the carrier gas to identify any possible type of product. The column oven was maintained at $50{ }^{\circ} \mathrm{C}$ for $1 \mathrm{~min}$ followed by a temperature ramp at $10{ }^{\circ} \mathrm{C} / \mathrm{min}$ to $110^{\circ} \mathrm{C}$ which was held constant for $1 \mathrm{~min}$ for a precise product analysis. In order to measure the selectivity of the system, the signal response of the FID and TCD to each gaseous product was calibrated by analyzing a series of standard gas mixtures with known compositions prior to the experiments.

We also performed differential electrochemical mass spectroscopy (DEMS, HPR-40 DEMS, Hidden Analytical) to precisely quantify all the possible electrochemical $\mathrm{CO}_{2}$ reduction reaction products using different catalysts. To do so, a custom-made two-compartment three-electrode electrochemical cell filled with $\mathrm{CO}_{2}$ saturated $1 \mathrm{M} \mathrm{KHCO}_{3}$ solution was used to conduct the reaction. The working electrode (cathode) was prepared by drop casting the synthesized catalysts on a gas diffusion electrode (GDL) electrode with a mass loading of $0.1 \mathrm{mg} / \mathrm{cm}^{2}$. Platinum (Pt) gauze 52 mesh (Alfa Aesar) and $\mathrm{Ag} / \mathrm{AgCl}$ (BASi) were used as counter and reference electrodes, respectively. The cathode and anode parts of the cell were separated through a Nafion membrane to eliminate the effect of product oxidation at the anode surface. The cell was perfectly sealed to prevent any leakage.

Then, we performed the chronoamperometry (CA) experiment at different potentials for $60 \mathrm{~min}$. Prior to the experiment, the signal responses of the DEMS instrument for different products were calibrated by injecting and analyzing a series of standard samples (e.g., $\mathrm{H}_{2}, \mathrm{CO}, \mathrm{CH}_{4}$, etc.) with 
known concentrations prior to the experiment. In detail, for each possible product (e.g., $\mathrm{H}_{2}, \mathrm{CO}$, $\mathrm{CH}_{4}$, etc.), Five different known concentrations were prepared in a sealed gas bag (Tadler® Sample Bag, SKC) by mixing known volume of sample and the Ar gas. Then, $1 \mathrm{~mL}$ of each prepared concentration was injected to the DEMS instrument using a sample locked syringe (Hamilton). Once injected, immediate increase in the $\mathrm{m} / \mathrm{z}$ signal for each sample was observed. The corresponding moles of each gas (e.g., $\mathrm{H}_{2}, \mathrm{CO}, \mathrm{CH}_{4}$, etc.) in each sample were calculated using the governing standard temperature and pressure condition where 1 mole of gas has a volume of 22.4 Lit at a pressure of $1 \mathrm{~atm}$. Then, the calibration curves were plotted using the number of moles of the gas (e.g., $\mathrm{H}_{2}, \mathrm{CO}, \mathrm{CH}_{4}$, etc.) versus the surface area under the pressuretime curve (Figure S13).
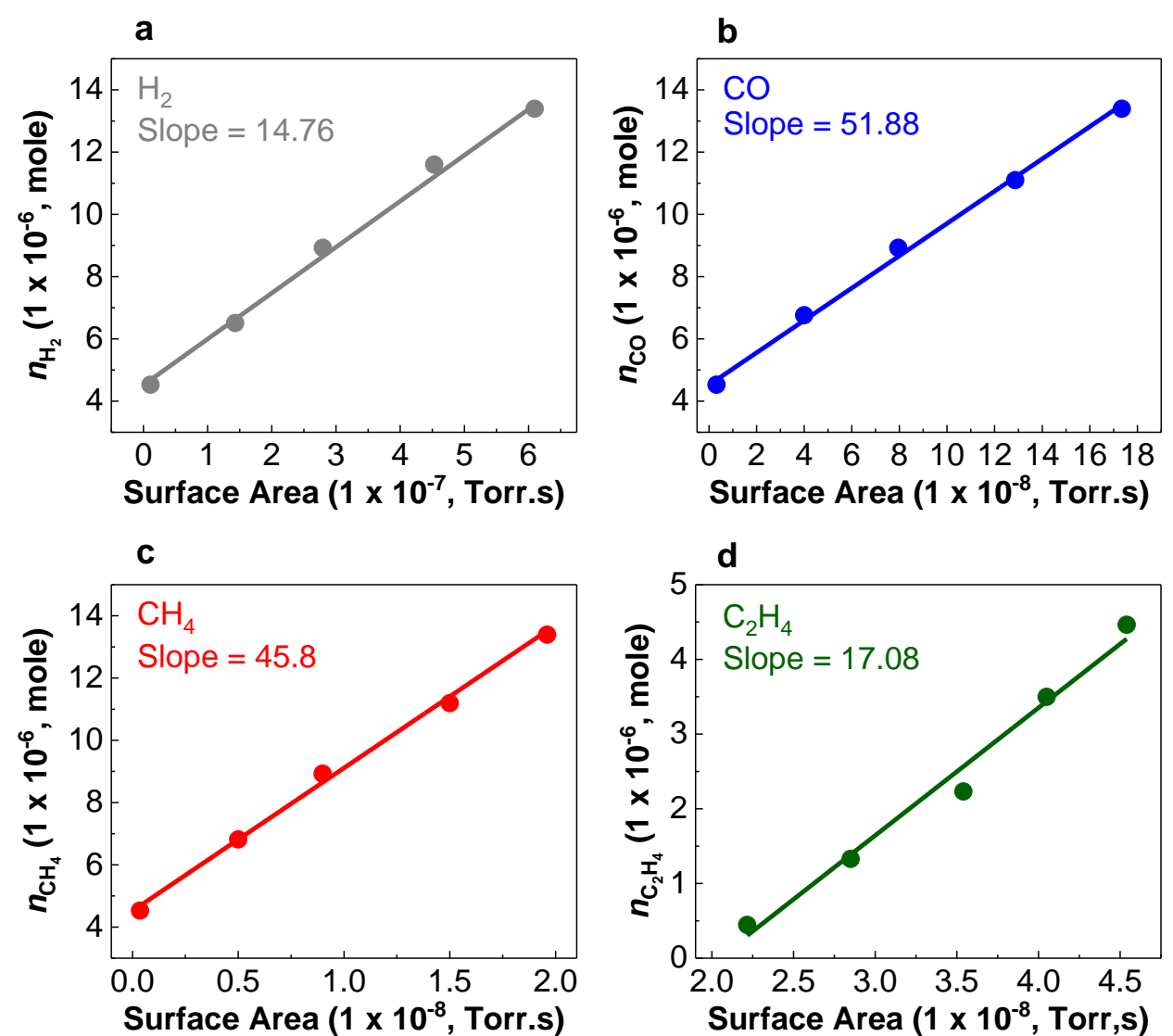

Figure S13. Calibration curve for product selectivity analysis using DEMS instrument. The plots show the calibration data for (a) $\mathrm{H}_{2}$ (b) $\mathrm{CO}$ (c) $\mathrm{CH}_{4}$ (d) $\mathrm{C}_{2} \mathrm{H}_{4}$. 
We have also performed nuclear magnetic resonance (NMR) spectroscopy on the electrolyte after $\mathrm{CO}_{2}$ reduction reaction. Electrochemical $\mathrm{CO}_{2}$ reduction reaction were conducted using the two-compartment tree-electrode cell filled with $1 \mathrm{M} \mathrm{KHCO}_{3}(\mathrm{pH}$ of 8.0$)$. Chronoamperometry (CA) experiments were performed for the specific amount of time at different potentials. To analyze the products of the $\mathrm{CO}_{2}$ reduction reaction, $0.5 \mathrm{~mL}$ of the electrolyte was taken and mixed with 0.2 $\mathrm{mL}$ Deutrium oxide ( $\mathrm{D}_{2} \mathrm{O} 99.9 \%$ deuterium, Sigma-Aldrich) in $5 \mathrm{~mm}$ NMR glass tube (Wilmad®). ${ }^{1} \mathrm{H}$ NMR spectroscopy experiment was carried out using a $500 \mathrm{MHz}$ Bruker Advance III HD system equipped with a TXO Prodigy probe with Z-gradient for enhanced sensitivity $\left({ }^{1} H=1200\right)$ at 298 $\mathrm{K}$. The NMR experiments indicate the formation of formate $(\mathrm{HCOO})$, methanol $\left(\mathrm{CH}_{3} \mathrm{OH}\right)$ and ethanol $\left(\mathrm{C}_{2} \mathrm{H}_{5} \mathrm{OH}\right)$ as the liquid products. The relative areas observed in the NMR spectra for all products were calculated by normalizing against the peak area of $\mathrm{D}_{2} \mathrm{O}(0.2 \mathrm{~mL})$. To calculate the selectivity of the catalysts at different applied potential, we used the Equation S4 to measure the faradaic efficiencies (FEs).

$$
F E \%=\frac{\text { experimental moles of product }}{\text { theoretical moles of product }}=\frac{\text { moles of product }(\text { measured by DEMS) }}{\frac{j\left(\frac{m A}{c m^{2}}\right) \times t(S)}{n \times F}} \times 100,(\text { Equation S4) }
$$

Where in Equation S4, the theoretical moles of each product was also extracted by dividing number of coulombs (measured by calculating the curve area of the current density vs time plot obtained in CA experiment) over the number of electrons required (n) for formation of each product e.g., $\mathrm{CO}, \mathrm{CH}_{4}$ and $\mathrm{H}_{2}\left(\mathrm{n}_{\mathrm{CO}}=2, \mathrm{n}_{\mathrm{CH}}=8, \mathrm{n}_{\mathrm{H} 2}=2\right)$ multiplied by Faraday number $(96,485$ $\mathrm{C} /$ mole). Figures S14a-e show faradaic efficiency (FE) results of different sizes OFn-Cu nanoparticles compared with the $\mathrm{Cu}(5 \mathrm{~nm})$ and treated $\mathrm{Cu}$ foil. As shown in these figures, the $\mathrm{CH}_{4}$ and $\mathrm{C}_{2} \mathrm{H}_{4}$ formation onset potentials are about $-0.85 \mathrm{~V}$ for $\mathrm{OFn}-\mathrm{Cu}$ nanoparticles. However, $\mathrm{CH}_{4}$ is formed at potential of $-1.05 \mathrm{~V}$ with $\mathrm{FE}$ of $8.12 \%$ and $3.82 \%$ for the $\mathrm{Cu}(5 \mathrm{~nm})$ and treated $\mathrm{Cu}$ foil, respectively where $\mathrm{OFn}-\mathrm{Cu}(5 \mathrm{~nm})$ showed the maximum $\mathrm{CH}_{4}$ formation $\mathrm{FE}$ of $60.6 \%$ at this potential. Furthermore, the highest $\mathrm{CH}_{4}$ formation $\mathrm{FE}$ of $43.11 \%$, and $54.79 \%$ are calculated 
for OFn-Cu $(1 \mathrm{~nm})$, and OFn-Cu $(5 \mathrm{~nm})$ at a potential of $-1.05 \mathrm{~V}$. As shown in Figure $\mathrm{S} 14, \mathrm{C}_{2} \mathrm{H}_{5} \mathrm{OH}$ and $\mathrm{CH}_{3} \mathrm{OH}$ formation onset potential are $-0.95 \mathrm{~V}$ for $\mathrm{OFn}-\mathrm{Cu}(1-15 \mathrm{~nm})$ nanoparticles whereas these two products are formed at higher potential of $-1.05 \mathrm{~V}$ for $\mathrm{Cu}(5 \mathrm{~nm})$ and treated $\mathrm{Cu}$ foil. Moreover, the maximum $\mathrm{C}_{2} \mathrm{H}_{5} \mathrm{OH}$ and $\mathrm{CH}_{3} \mathrm{OH}$ formation $\mathrm{FE}$ of $13.65 \%$ and $4.14 \%$ were obtained, respectively, at a potential of $-1.25 \mathrm{~V}$ for $\mathrm{OFn}-\mathrm{Cu}(5 \mathrm{~nm})$ nanoparticles. However, formate is mainly produced at potential of $-0.85 \mathrm{~V}$ (FE of $4.85 \%$ ) while the formate formation FE drops to $0.57 \%$ at $-1.25 \mathrm{~V}$ for OFn- $\mathrm{Cu}(5 \mathrm{~nm})$. The results for OFn-Cu $(5 \mathrm{~nm})$ nanoparticles shown in Figure $\mathrm{S} 14$ also indicate that a total FE of $87.58 \%$ for gas products and a total FE of $6.54 \%$ for liquid products at a potential of $-1.05 \mathrm{~V}$, resulting in an overall FE of $94.12 \% \pm 6$. Similarly, at a potential of $-1.25 \mathrm{~V}$, the total FE for gas and liquid products are $74.11 \%$ and $18.37 \%$, respectively, resulting in an overall FE of $92.48 \% \pm 7$.
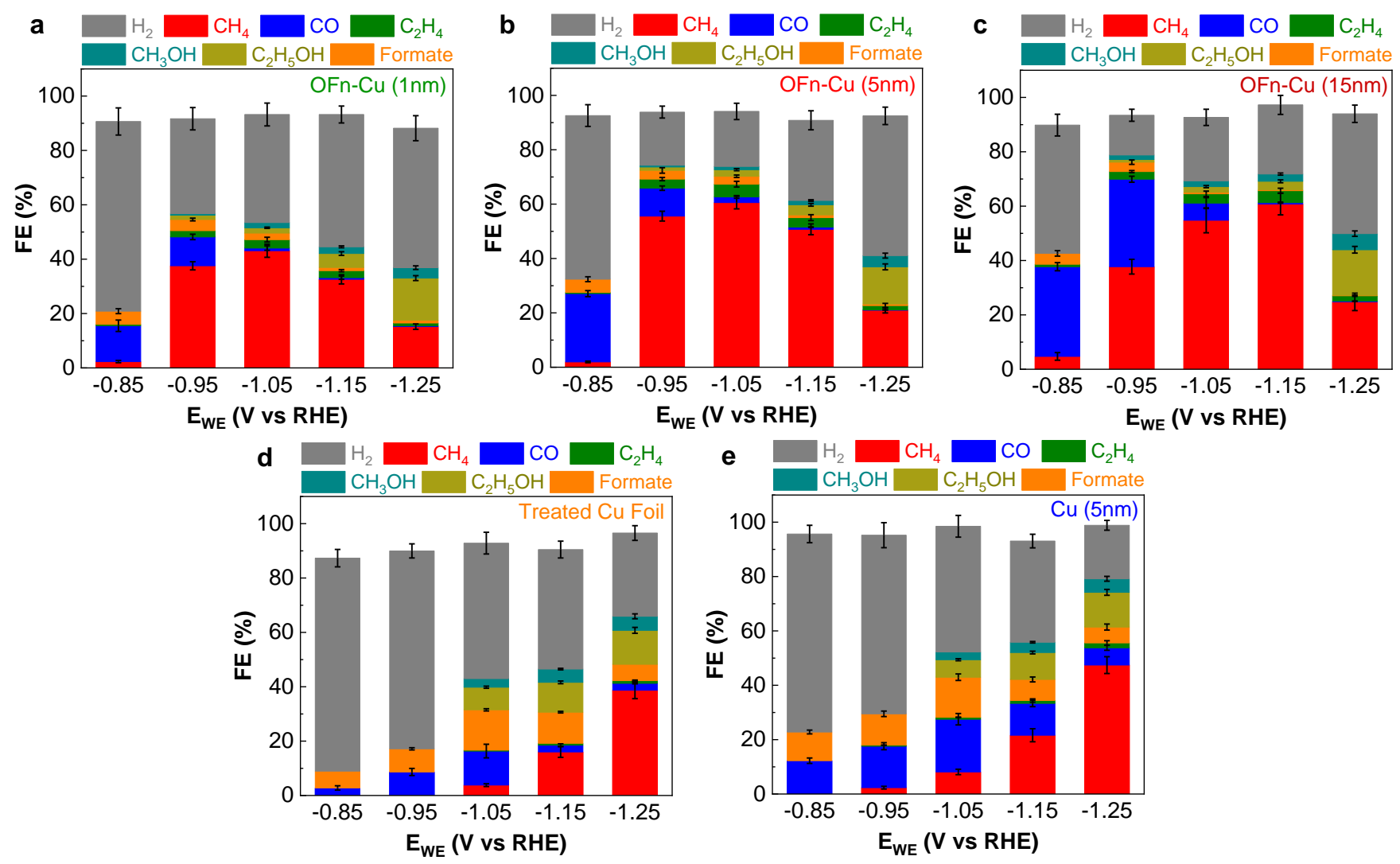

Figure S14. Faradaic efficiency measurements for (a) OFn- $\mathrm{Cu}(1 \mathrm{~nm})(\mathbf{b}) \mathrm{OFn}-\mathrm{Cu}(5 \mathrm{~nm})$ (c) OFn-Cu $(15 \mathrm{~nm})(\mathrm{d}) \mathrm{Cu}(5 \mathrm{~nm})(\mathrm{e})$ treated $\mathrm{Cu}$ foil. 
We have also summarized our FE measurements for each catalyst in Table S4.

Table S4. Summary of FE results for each catalyst

\begin{tabular}{|c|c|c|c|c|c|c|c|}
\hline OFn-Cu (1nm) & \multicolumn{7}{|c|}{ Products } \\
\hline Potential & $\mathbf{C H}_{4}$ & $\mathbf{C O}$ & $\mathbf{C}_{2} \boldsymbol{H}_{4}$ & Formate & $\boldsymbol{H}_{2}$ & $\mathbf{C H}_{3} \mathbf{O H}$ & $\mathbf{C}_{2} \boldsymbol{H}_{5} \mathbf{O H}$ \\
\hline-0.85 & 2.31 & 13.19 & 0.51 & 4.86 & 69.78 & - & - \\
\hline-0.95 & 37.56 & 10.62 & 2.3 & 4.1 & 34.91 & 0.58 & 1.57 \\
\hline-1.05 & 43.10 & 0.97 & 3.12 & 2.37 & 39.76 & 1.90 & 1.98 \\
\hline-1.15 & 32.59 & 0.58 & 2.6 & 1.19 & 48.68 & 2.46 & 5.11 \\
\hline-1.25 & 15.19 & 0.27 & 1.04 & 0.97 & 51.32 & 3.81 & 15.57 \\
\hline
\end{tabular}

\begin{tabular}{|c|c|c|c|c|c|c|c|}
\hline OFn-Cu (5nm) & \multicolumn{7}{|c|}{ Products } \\
\hline Potential & $\mathbf{C H}_{4}$ & $\mathbf{C O}$ & $\mathbf{C}_{2} \boldsymbol{H}_{4}$ & Formate & $\boldsymbol{H}_{2}$ & $\mathbf{C H}_{3} \mathbf{O H}$ & $\mathbf{C}_{2} \boldsymbol{H}_{5} \mathbf{O H}$ \\
\hline-0.85 & 1.95 & 25.13 & 0.45 & 4.85 & 60.20 & - & - \\
\hline-0.95 & 55.59 & 10.29 & 3.32 & 3.19 & 19.55 & 0.63 & 1.26 \\
\hline-1.05 & 60.57 & 2.06 & 4.72 & 2.9 & 20.23 & 1.21 & 2.41 \\
\hline-1.15 & 50.73 & 0.79 & 3.52 & 0.98 & 29.51 & 1.56 & 3.75 \\
\hline-1.25 & 20.97 & 0.11 & 1.61 & 0.57 & 51.42 & 4.14 & 13.65 \\
\hline
\end{tabular}

\begin{tabular}{|c|c|c|c|c|c|c|c|}
\hline OFn-Cu (15nm) & \multicolumn{7}{|c|}{ Products } \\
\hline Potential & $\mathbf{C H}_{4}$ & $\mathbf{C O}$ & $\mathbf{C}_{2} \boldsymbol{H}_{4}$ & Formate & $\boldsymbol{H}_{\mathbf{2}}$ & $\mathbf{C H}_{3} \mathbf{O H}$ & $\mathbf{C}_{2} \boldsymbol{H}_{5} \mathbf{O H}$ \\
\hline-0.85 & 4.73 & 33.00 & 0.91 & 3.99 & 47.19 & - & - \\
\hline-0.95 & 37.73 & 32.18 & 2.88 & 3.46 & 14.63 & 1.64 & 0.98 \\
\hline-1.05 & 54.42 & 6.34 & 3.46 & 0.57 & 23.37 & 2.09 & 2.09 \\
\hline-1.15 & 59.71 & 0.50 & 4.41 & 0.38 & 25.45 & 2.66 & 3.07 \\
\hline-1.25 & 24.79 & 0.24 & 2.31 & 0.19 & 44.10 & 5.92 & 16.73 \\
\hline
\end{tabular}

\begin{tabular}{|c|c|c|c|c|c|c|c|}
\hline Treated Cu Foil & \multicolumn{7}{|c|}{ Products } \\
\hline Potential & $\mathbf{C H}_{4}$ & $\mathbf{C O}$ & $\boldsymbol{C}_{2} \boldsymbol{H}_{4}$ & Formate & $\boldsymbol{H}_{2}$ & $\mathbf{C H}_{3} \mathbf{O H}$ & $\mathbf{C}_{2} \boldsymbol{H}_{5} \mathbf{O H}$ \\
\hline-0.85 & - & 2.78 & - & 6.17 & 78.36 & - & - \\
\hline-0.95 & - & 8.65 & - & 8.52 & 72.79 & - & - \\
\hline-1.05 & 3.81 & 12.53 & 0.33 & 14.83 & 49.85 & 3.14 & 8.32 \\
\hline-1.15 & 16.02 & 2.48 & 0.67 & 11.46 & 43.96 & 4.89 & 10.96 \\
\hline-1.25 & 38.71 & 2.34 & 1.02 & 5.98 & 30.65 & 5.15 & 12.51 \\
\hline
\end{tabular}

\begin{tabular}{|c|c|c|c|c|c|c|c|}
\hline $\mathbf{C u}(5 \mathrm{~nm})$ & \multicolumn{7}{|c|}{ Products } \\
\hline Potential & $\mathbf{C H}_{4}$ & $\mathbf{C O}$ & $\mathbf{C}_{2} \boldsymbol{H}_{4}$ & Formate & $\boldsymbol{H}_{\mathbf{2}}$ & $\mathbf{C H}_{3} \mathbf{O H}$ & $\mathbf{C}_{2} \boldsymbol{H}_{5} \mathbf{O H}$ \\
\hline-0.85 & - & 12.26 & - & 10.54 & 72.85 & - & - \\
\hline-0.95 & 2.34 & 15.24 & 0.38 & 11.53 & 65.72 & - & - \\
\hline-1.05 & 8.11 & 19.39 & 0.7 & 14.76 & 46.21 & 2.87 & 6.43 \\
\hline-1.15 & 21.61 & 11.71 & 1.06 & 7.75 & 37.22 & 3.78 & 9.89 \\
\hline-1.25 & 47.43 & 6.35 & 1.88 & 5.83 & 19.67 & 4.98 & 12.78 \\
\hline
\end{tabular}

\section{S8- ${ }^{13} \mathrm{C}$ labeled carbon dioxide experiment}

The $\mathrm{CO}_{2}$ reduction reaction experiments using ${ }^{13} \mathrm{C}$ labeled $\mathrm{CO}_{2}\left({ }^{13} \mathrm{CO}_{2}\right)$ were performed to verify the source of carbon for products such as $\mathrm{CH}_{4}$ in our system. To do this, a custom-made two-compartment three-electrode electrochemical cell filled with $1 \mathrm{M} \mathrm{KHCO}_{3}$ solution was used to perform the $\mathrm{CO}_{2}$ reduction reaction as shown in Figure S11. The working electrode (cathode) was prepared by drop casting the synthesized OFn-Cu $(5 \mathrm{~nm})$ catalyst on a customized glassy carbon 
(GC) electrode with a catalyst loading of $0.1 \mathrm{mg} / \mathrm{cm}^{2}$. Platinum (Pt) gauze 52 mesh (Alfa Aesar) and $\mathrm{Ag} / \mathrm{AgCl}$ (BASi) were used as counter and reference electrodes, respectively. The cathode and anode parts of the cell were separated by a Nafion membrane to eliminate the effect of product oxidation at the anode surface. The cell was perfectly sealed to prevent any leakage from the head space of the cell. At first, we purged Argon (ultra-high purity grade, Airgas) into the solution with a flow rate of $30 \mathrm{~mL} / \mathrm{min}$ for 20 min to remove all dissolved gasses from the electrolyte. Next, the ${ }^{13} \mathrm{CO}_{2}$ (Sigma Aldrich) was bubbled into the cell to saturate the electrolyte. Then, we performed the chronoamperometry (CA) experiment at a potential of $-1.05 \mathrm{~V} v s \mathrm{RHE}$ for $60 \mathrm{~min}$. The CA experiment result for the OFn-Cu $(5 \mathrm{~nm})$ nanoparticles in ${ }^{13} \mathrm{CO}_{2}$ saturated $1 \mathrm{M}$ $\mathrm{KHCO}_{3}$ is shown in Figure S15, indicating an average current density of about $50 \mathrm{~mA} / \mathrm{cm}^{2}$. Once the CA experiment was finished, $1 \mathrm{~mL}$ sample from the headspace of the electrochemical cell was collected using a sample locked syringe (Hamilton) and then injected into the differential electrochemical mass spectrometer (DEMS, HPR-40, Hiden Analytical) to analyze the types of products in the cell. This mass spectrometer is connected to the ultra-vacuum pressure to detect any possible products with a partial pressure as low as $1.0 \times 10^{-13}$ Torr. We used bar detection mode to measure peak intensities of mass to charge $(\mathrm{m} / \mathrm{z})$ ratio of 1 to 60 with the scan rate of 0.2 second per scan (Figure S16). All recorded data were analyzed by using MASoft 7 professional software (Hiden Analytical).

The DEMS bar mode analysis of the $1 \mathrm{~mL}$ sample is shown in Figure S16. The result of the Figure $\mathrm{S} 16 \mathrm{a}$ and $\mathrm{b}$ show the DEMS bar diagram results for after and before $1 \mathrm{~mL}$ sample injection, respectively. The final data obtained by subtracting DEMS results before and after the sample injection are also shown in Figure S16c, indicating ${ }^{13} \mathrm{C}$ labeled hydrocarbon products at different $\mathrm{m} / \mathrm{z}$ ratios. As shown in this figure, two peaks with relatively high intensities are observed at $\mathrm{m} / \mathrm{z}=17$ and $\mathrm{m} / \mathrm{z}=29$, corresponding to the formation of ${ }^{13} \mathrm{CH}_{4}$ and ${ }^{13} \mathrm{CO}$ products. Figure $\mathrm{S} 16 \mathrm{c}$ also shows ${ }^{13} \mathrm{C}(\mathrm{m} / \mathrm{z}=13),{ }^{13} \mathrm{C}_{2} \mathrm{H}_{4}(\mathrm{~m} / \mathrm{z}=30)$ and ${ }^{13} \mathrm{CO}_{2}(\mathrm{~m} / \mathrm{z}=45)$ peaks, suggesting formation of 
other hydrocarbon products such as ethylene $\left(\mathrm{C}_{2} \mathrm{H}_{4}\right)$. Moreover, as shown in Figure S16c, no peaks are observed at $\mathrm{m} / \mathrm{z}=12,16$ and 28 (corresponding to ${ }^{12} \mathrm{C},{ }^{12} \mathrm{CH}_{4},{ }^{12} \mathrm{CO}$ and ${ }^{12} \mathrm{C}_{2} \mathrm{H}_{4}$, respectively), confirming that the products are produced by ${ }^{13} \mathrm{C}$ labeled $\mathrm{CO}_{2}$ as the available reactant in the experiment.

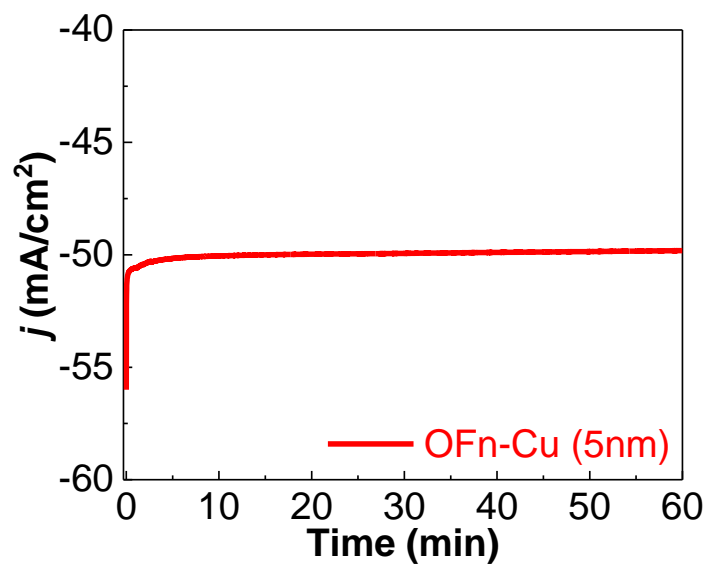

Figure S15. The chronoamperometry (CA) experiment results for OFn-Cu (5 nm) in the two-compartment three-electrode electrochemical cell using ${ }^{13} \mathrm{CO}_{2}$ saturated $1 \mathrm{M} \mathrm{KHCO}_{3}$ solution.
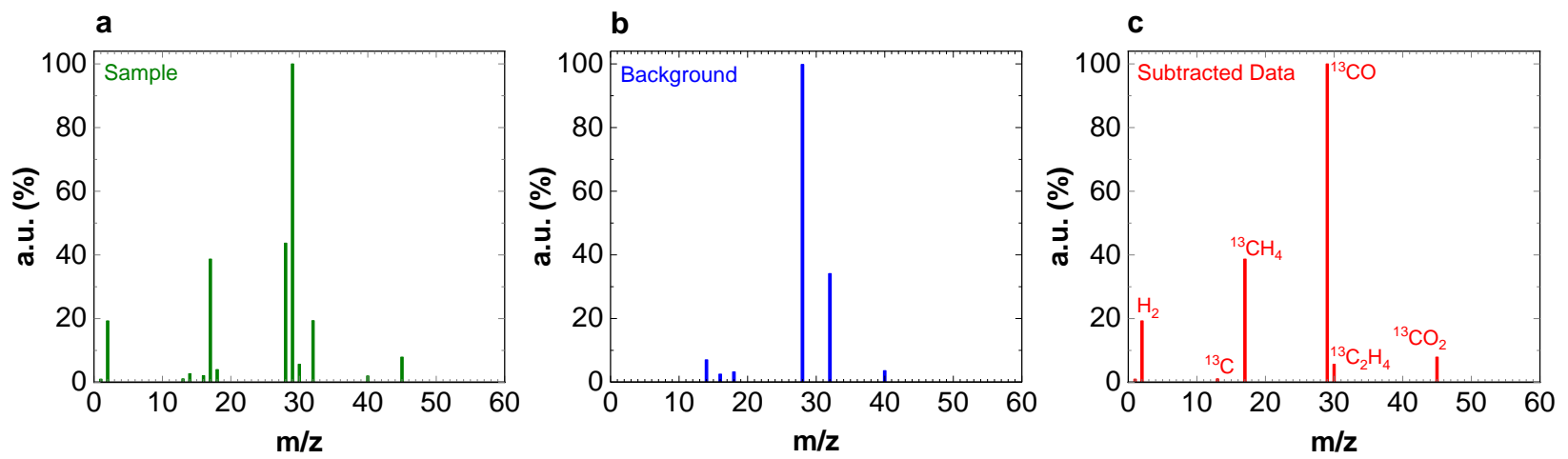

Figure S16. Mass spectroscopy analysis of $1 \mathrm{~mL}$ gas sample extracted from sealed two-compartment three-electrode cell in different mass-to-charge $(\mathrm{m} / \mathrm{z})$ ratios. (a) Raw sample data after injecting $1 \mathrm{~mL}$ sample to DEMS (b) Background data (c) Deconvoluted data which is concluded from subtracting raw sample data from background data.

To further confirm this, we also measured the partial pressure variation of the possible products with respect of time using the multiple ion detection (MID) mode. This experiment allows to precisely determine the source of possible formed ${ }^{13} \mathrm{C}$ labeled products $\left({ }^{13} \mathrm{CH}_{4},{ }^{13} \mathrm{CO},{ }^{13} \mathrm{C}_{2} \mathrm{H}_{4}\right.$, ${ }^{13} \mathrm{CO}_{2}$ ) in this study. To do this, $\mathrm{m} / \mathrm{z}$ ratios of $13,17,29,30$ and 45 were selected for detection of ${ }^{13} \mathrm{C}(\mathrm{m} / \mathrm{z}=13),{ }^{13} \mathrm{CH}_{4}(\mathrm{~m} / \mathrm{z}=17),{ }^{13} \mathrm{CO}(\mathrm{m} / \mathrm{z}=29),{ }^{13} \mathrm{C}_{2} \mathrm{H}_{4}(\mathrm{~m} / \mathrm{z}=30)$ and ${ }^{13} \mathrm{CO}_{2}(\mathrm{~m} / \mathrm{z}=45)$, respectively. Figure S17a-f show the results of MID mode spectra obtained by injecting $1 \mathrm{~mL}$ sample from the 
headspace of the cell to the DEMS using a sample locked syringe (Hamilton) after a 60 minutes CA experiment. As shown in these figures, immediate increase in the partial pressures of different products (different $\mathrm{m} / \mathrm{z}$ ratios) after the injection confirm that the ${ }^{13} \mathrm{C}$ labeled $\mathrm{CO}_{2}$ gas is as the main source of the formed products in the $\mathrm{CO}_{2}$ reduction reaction.
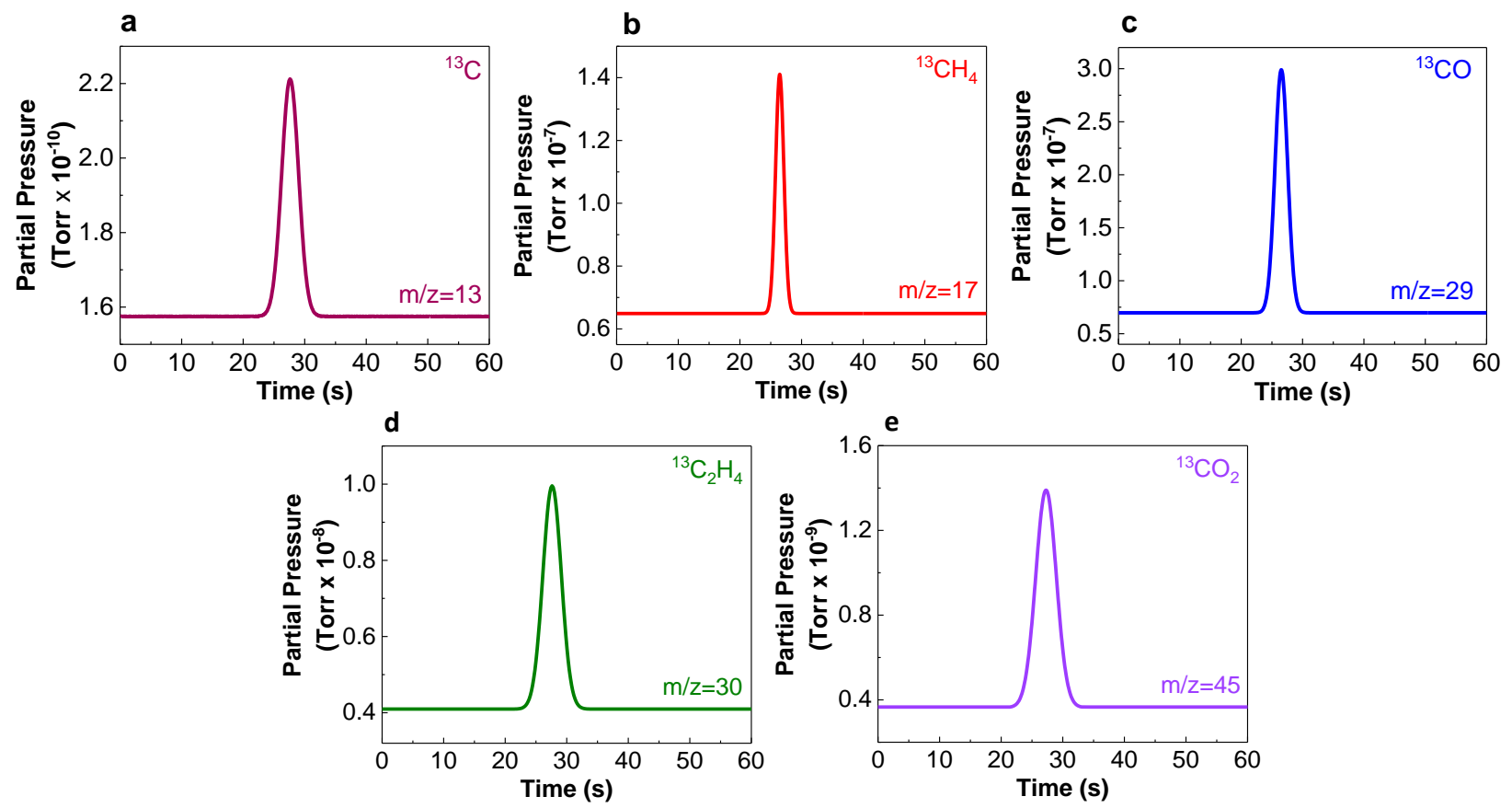

Figure S17. The multiple ion detection (MID) signals of (a) ${ }^{13} \mathrm{C}$, (b) ${ }^{13} \mathrm{CH}_{4}$, (c) ${ }^{13} \mathrm{CO}$, (d) ${ }^{13} \mathrm{C}_{2} \mathrm{H}_{4}$ and (e) ${ }^{13} \mathrm{CO}_{2}$ obtained in a CA experiment using OFn-Cu $(5 \mathrm{~nm})$ in ${ }^{13} \mathrm{CO}_{2}$-saturated $1 \mathrm{M} \mathrm{KHCO}_{3}$ electrolyte in the two-compartment three-electrode cell.

\section{S9- Number of active sites and turnover frequency (TOF) measurements}

Turnover frequency (TOF) measurements, normalized activity per active sites, were performed to characterize the intrinsic catalytic active sites in each catalyst using the roughness factor (RF) technique. ${ }^{26-28}$ The RF number for each catalyst was calculated with respect to its double layer capacitor $\left(\mathrm{C}_{\mathrm{dll}}\right)$ compared with its corresponding standard flat capacitor. To calculate the $\mathrm{C}_{\mathrm{dl}}$, first the cyclic voltammetry (CV) experiments for OFn-Cu $(1,5$ and $15 \mathrm{~nm}), \mathrm{Cu}(5 \mathrm{~nm})$ and treated $\mathrm{Cu}$ foil were performed in the $0.5 \mathrm{M} \mathrm{H}_{2} \mathrm{SO}_{4}$ at different scan rates e.g., 10, 30, 50, 70, 90, 110, $130,150,170$ and $190 \mathrm{mV} / \mathrm{s}$ in the non-faradaic region. All experiments were performed in a threeelectrode electrochemical cell using a customized glassy carbon electrode with a surface area of 
$1 \mathrm{~cm}^{2}$ and a catalyst mass loading of $0.1 \mathrm{mg}$. Pt gauze 52 mesh and $\mathrm{Ag} / \mathrm{AgCl}$ electrodes were used as the counter and the reference electrodes. Figure S18 shows the CV curves obtained for each catalyst in the non-faradaic region. Figure S18a indicates a very small oxidative feature at $\sim 0.04 \mathrm{~V}$ which can be attributed to the chemical adsorption/desorption of the possible ions such as $\mathrm{SO}_{4}{ }^{2-}$ in the electrolyte solution $\left(0.5 \mathrm{M} \mathrm{H}_{2} \mathrm{SO}_{4}\right)$.
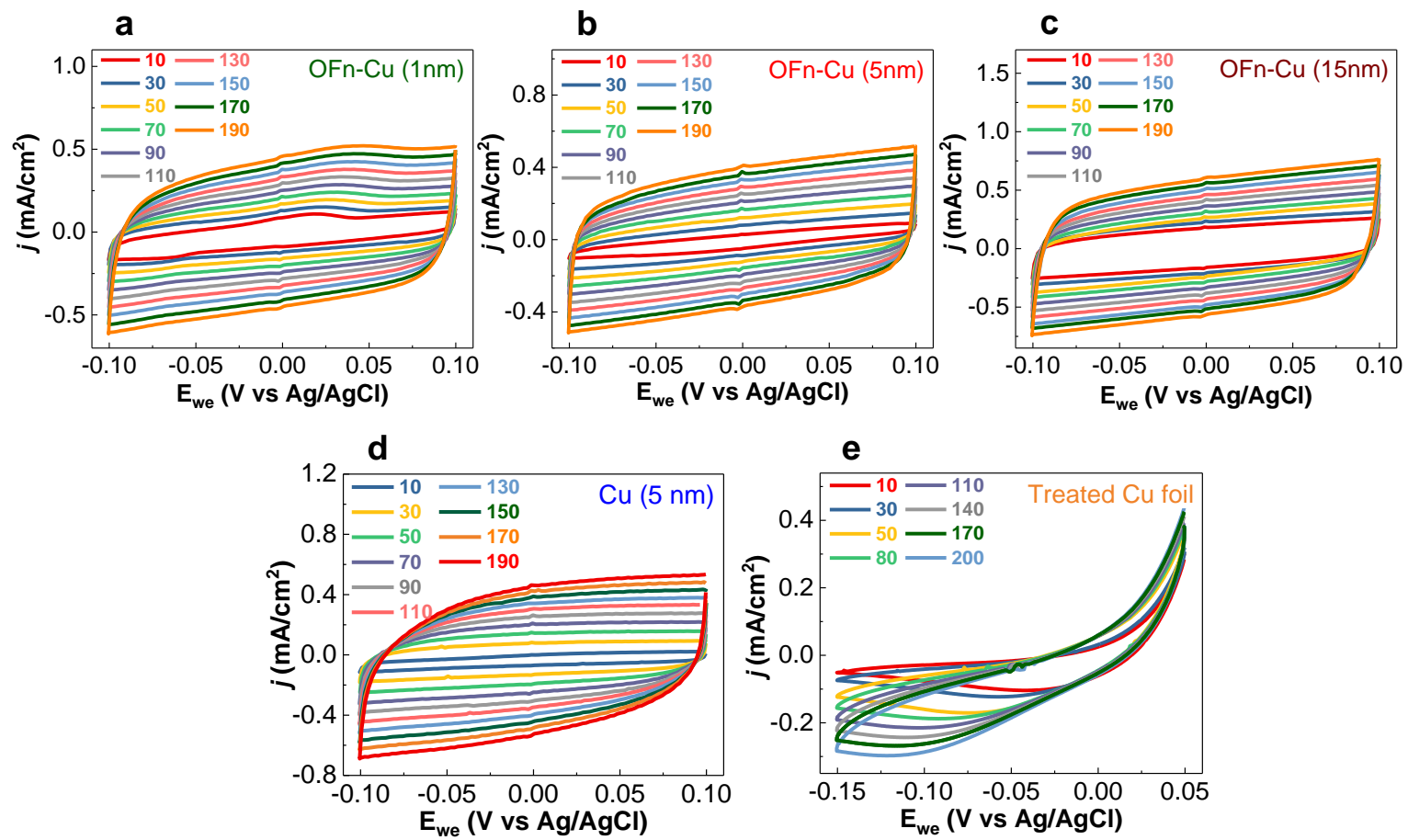

Figure S18. Cyclic Voltammetry (CV) curves of OFn-Cu (1,5 and $15 \mathrm{~nm}), \mathrm{Cu}(5 \mathrm{~nm})$ and treated Cu foil at different scan rates. The experiments were performed in $0.5 \mathrm{M} \mathrm{H}_{2} \mathrm{SO}_{4}$ electrolyte by sweeping the potential in the non-faradic region.

The $C_{d l}$ value for each catalyst was then extracted by reading the obtained current densities at a constant potential $\left(\mathrm{E}_{\mathrm{we}}=+0.025 \mathrm{~V} v \mathrm{Ag} / \mathrm{AgCl}\right)$ and the corresponding scan rates. 

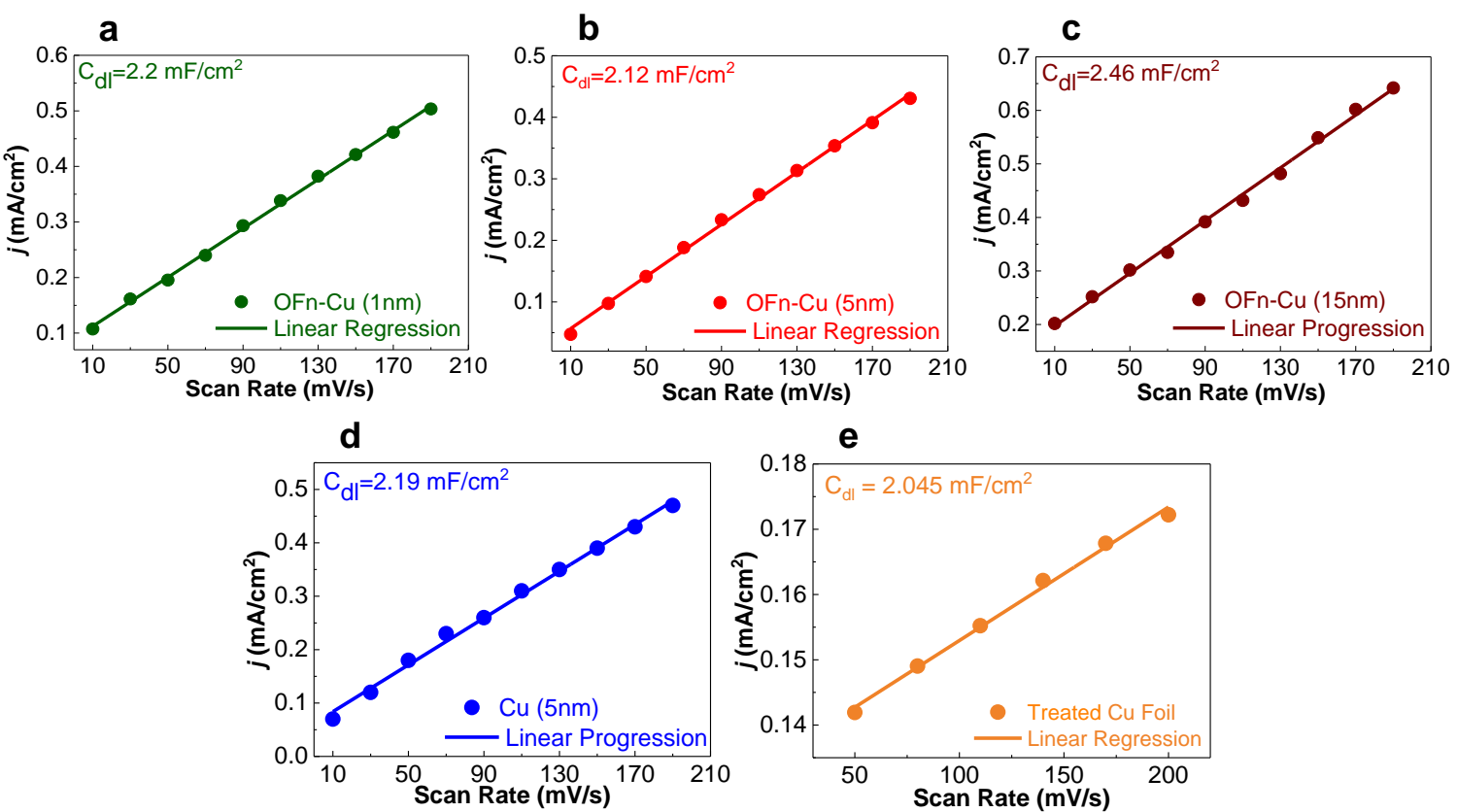

Figure S19. Double layer capacitance ( $\left.C_{d 1}\right)$ calculation for OFn-Cu $(1,5$ and $15 \mathrm{~nm}), \mathrm{Cu}(5 \mathrm{~nm})$ and treated $\mathrm{Cu}$ foil. Plots show the current density of CV experiments at potential $+0.025 \mathrm{~V} v s \mathrm{Ag} / \mathrm{AgCl}$ as a function of scan rates. The slope of these lines indicates $C_{d l}$ for each catalyst.

As shown in Figure $\mathrm{S} 19$, the measured $\mathrm{C}_{\mathrm{dl}}$ values for each catalyst, calculated from the slope of the "current density - scan rate" plot, are 2.2, 2.12, 2.46, 2.85 and $2.045 \mathrm{mF} / \mathrm{cm}^{2}$ for the 1, 5 and $15 \mathrm{~nm}$ OFn-Cu nanoparticles, $\mathrm{Cu}(5 \mathrm{~nm})$, and treated Cu foil, respectively.

The RF number was then calculated from Equation S5 using the measured $\mathrm{C}_{\mathrm{dl}}$ values where the flat standard capacitance is extracted from literature.

$$
R F=\frac{C_{d l}}{\text { flat standard capacitor }}, \quad \text { (Equation S5) }
$$

A summary of RF calculation for the synthesized catalysts are shown in Table S5.

Table S5: A summary of RF measurements.

\begin{tabular}{lll}
\hline Catalyst & $\mathrm{Cdl}\left(\mathrm{mF} / \mathrm{cm}^{2}\right)$ & Roughness factor $(\mathrm{RF})$ \\
\hline OFn-Cu $(1 \mathrm{~nm})$ & 2.200 & 36.66 \\
OFn-Cu $(5 \mathrm{~nm})$ & 2.120 & 35.33 \\
OFn-Cu $(15 \mathrm{~nm})$ & 2.460 & 41.00 \\
$\mathrm{Cu}(5 \mathrm{~nm})$ & 2.850 & 47.50 \\
Treated Cu foil & 2.045 & 34.08 \\
\hline
\end{tabular}


The calculated number of active sites for each catalyst was then obtained using the Equation S6.

$$
\begin{aligned}
& \text { Density of active sites for the catalyst }(\text { Sites } / \mathrm{cm} 2)= \\
& \text { Density of active sites for the flat standard sample }\left(\frac{\text { Sites }}{\mathrm{cm} 2}\right) \times R F \text { (Equation S6) }
\end{aligned}
$$

Next, the $\mathrm{CH}_{4}$ formation TOF of each catalyst in the $\mathrm{CO}_{2}$ reduction reaction inside the $\mathrm{CO}_{2}$ saturated $1 \mathrm{M} \mathrm{KHCO}_{3}$ was determined using the Equation $\mathrm{S} 7$ at different potentials. ${ }^{26-28}$

$$
\begin{aligned}
& \mathrm{CH}_{4} \text { formation TOF }\left(\mathrm{s}^{-1}\right)=\mathrm{j}\left(\mathrm{A} / \mathrm{cm}^{2}\right) \times \mathrm{CH}_{4} \text { formation } \mathrm{FE} /\left\{\left[\text { active sites density }\left(\mathrm{sites} / \mathrm{cm}^{2}\right)\right]\right. \\
& \left.\times\left[1.602 \times 10^{-19}\left(\mathrm{C} / \mathrm{e}^{-}\right)\right] \times\left[8 \mathrm{e}^{-} / \text {mole }^{2} \mathrm{CO}_{2}\right]\right\}(\text { Equation S7) }
\end{aligned}
$$

Figure $\mathrm{S} 20$ shows the $\mathrm{CH}_{4}$ formation TOF measurements of OFn-Cu nanoparticles, $\mathrm{Cu}(5 \mathrm{~nm})$ and treated Cu foil.

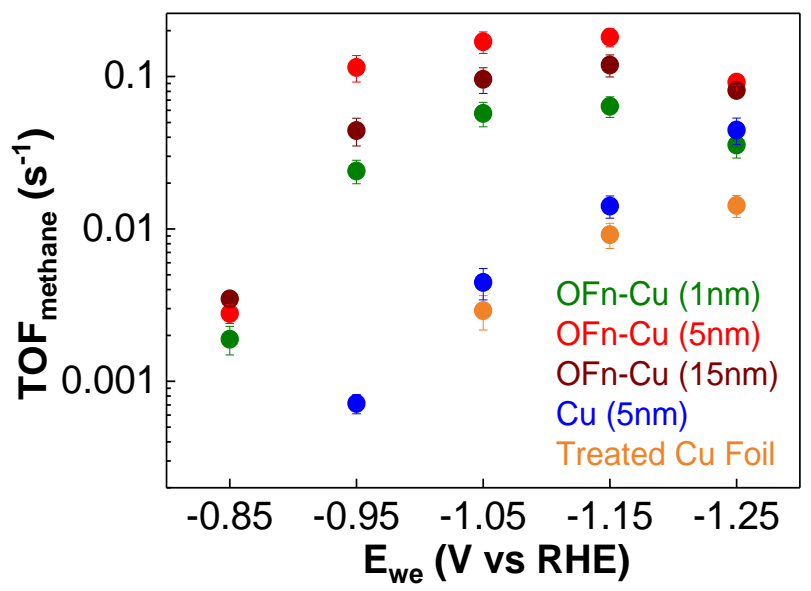

Figure S20. Methane formation TOF measurements of OFn-Cu nanoparticles, $\mathrm{Cu}(5 \mathrm{~nm})$ and treated $\mathrm{Cu}$ foil.

\section{S10- Tafel plots of OFn-Cu (5 nm), Cu (5 nm) and treated Cu foil}

The Tafel plots for $\mathrm{CH}_{4}, \mathrm{CO}, \mathrm{C}_{2} \mathrm{H}_{4}$, formate, $\mathrm{CH}_{3} \mathrm{OH}$ and $\mathrm{C}_{2} \mathrm{H}_{5} \mathrm{OH}$ products were plotted to study the kinetic behavior for formation of each product using OFn-Cu ( $5 \mathrm{~nm})$ and compared it with treated $\mathrm{Cu}$ foil and $\mathrm{Cu}(5 \mathrm{~nm})$ nanoparticles (Figure S21). Figure S21a-f show the Tafel plots for $\mathrm{CH}_{4}, \mathrm{CO}, \mathrm{C}_{2} \mathrm{H}_{4}$, formate and $\mathrm{CH}_{3} \mathrm{OH}, \mathrm{C}_{2} \mathrm{H}_{5} \mathrm{OH}$ products, respectively. As shown in Figure S21a for $\mathrm{CH}_{4}$ formation, the slope of the Tafel plot for OFn-Cu $(5 \mathrm{~nm})$ is $-59 \mathrm{mV} / \mathrm{dec}$ that is much lower than for the $\mathrm{Cu}(5 \mathrm{~nm})$ nanoparticles $(-140 \mathrm{mV} / \mathrm{dec})$ and treated $\mathrm{Cu}$ foil $(-155 \mathrm{mV} / \mathrm{dec})$. The 
observed Tafel slope of $-59 \mathrm{mV} / \mathrm{dec}$ in the low current density regime for $\mathrm{CH}_{4}$ formation using OFn-Cu $(5 \mathrm{~nm})$ suggest that $\mathrm{CHO} / \mathrm{COH}$ intermediate formation through $\mathrm{CO}$ hydrogenation process is the rate determining step. This is consistent with our DFT findings where the formation of $\mathrm{CHO}$ and $\mathrm{COH}$ intermediates is favored by transferring a proton to $\mathrm{CO}$ intermediate that is the rate determining step for methane formation. Moreover, the methane formation onset potential using OFn-Cu (5 nm) nanoparticles is $-0.85 \mathrm{~V} v \mathrm{RHE}$ that is 100 and $200 \mathrm{mV}$ lower than that of $\mathrm{Cu}(5 \mathrm{~nm})$ and treated $\mathrm{Cu}$ foil catalysts, suggesting higher methane formation activity for $\mathrm{OFn}-\mathrm{Cu}$ $(5 \mathrm{~nm})$ nanoparticles owing to its unique oxidation state at the surface (Figure S21a). Figure S21b$f$ also indicate that the Tafel slopes of the OFn-Cu $(5 n m)$ for $\mathrm{CO}, \mathrm{C}_{2} \mathrm{H}_{4}$, formate, $\mathrm{CH}_{3} \mathrm{OH}$ and $\mathrm{C}_{2} \mathrm{H}_{5} \mathrm{OH}$ formation are $-200,-34,-127,-269$ and $-205 \mathrm{mV} / \mathrm{dec}$, respectively. Moreover, the corresponding tafel slope for $\mathrm{Cu}(5 \mathrm{~nm})$ are $-176,-247,-327,-348$ and $-312 \mathrm{mV} / \mathrm{dec}$ and for treated Cu foil are $-135,-264,-264,-414$ and $-469 \mathrm{mV} / \mathrm{dec}$, respectively. As shown in these figures, the onset potential for $\mathrm{CO}, \mathrm{C}_{2} \mathrm{H}_{4}$, formate, $\mathrm{CH}_{3} \mathrm{OH}$ and $\mathrm{C}_{2} \mathrm{H}_{5} \mathrm{OH}$ formation using OFn- $\mathrm{Cu}(5 \mathrm{~nm})$ are $0.75,-0.85,-0.75,-0.95$ and $-0.95 \vee v s$ RHE, respectively. However. The corresponding onset potentials for $\mathrm{Cu}(5 \mathrm{~nm})$ nanoparticles are $100 \mathrm{mV}$ higher compared to that of $\mathrm{OFn}-\mathrm{Cu}(5 \mathrm{~nm})$. The $\mathrm{CO}, \mathrm{C}_{2} \mathrm{H}_{4}$, formate, $\mathrm{CH}_{3} \mathrm{OH}$ and $\mathrm{C}_{2} \mathrm{H}_{5} \mathrm{OH}$ products also form at higher overpotentials when treated Cu foil is used. 

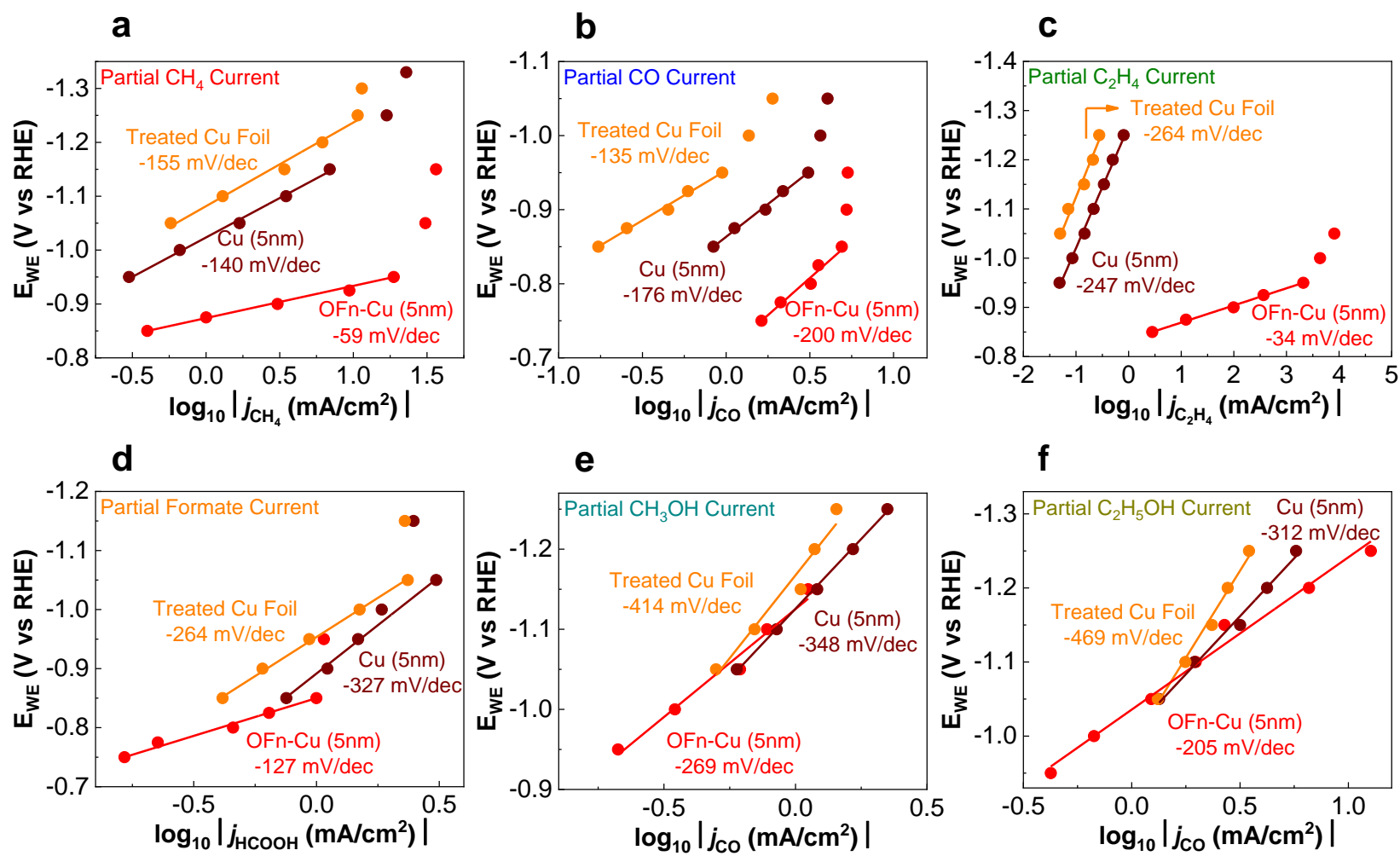

Figure S21. Tafel plots (potential vs partial current density of products formation) measured for OFn-Cu (5 $\mathrm{nm})$ nanoparticles, $\mathrm{Cu}(5 \mathrm{~nm})$ nanoparticles and treated Cu Foil.

\section{S11- In-situ Raman spectroscopy and stability experiments of OFn-Cu (5 nm) nanoparticles}

The long-term stability of OFn-Cu $(5 \mathrm{~nm})$ catalyst was tested by performing a chronoamperometry (CA) experiment at different potentials. The results shown in Figure S22 indicate that this catalyst operates up to one hour in a batch process with negligible decay in the performance.

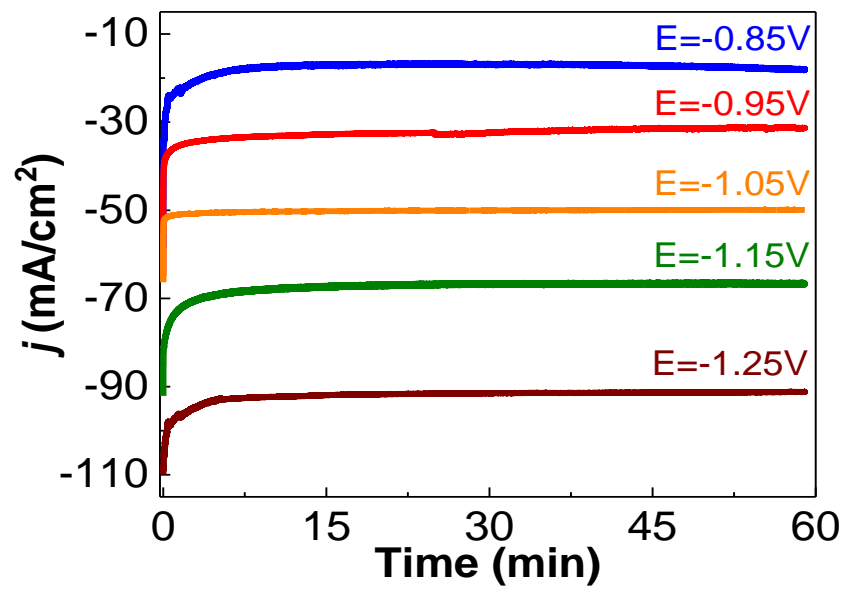

Figure S22. Long term stability performance of $\mathrm{OFn}-\mathrm{Cu}(5 \mathrm{~nm})$ in $\mathrm{CO}_{2}$ saturated $1 \mathrm{M} \mathrm{KHCO}_{3}$ 
To confirm the stability of oxidized layer of OFn-Cu $(5 \mathrm{~nm})$ nanoparticles under applied potential of $-1.05 \mathrm{~V}$ vs RHE, we performed in-situ Raman spectroscopy. A custom designed Raman electrochemical cell was used to do in-situ Raman experiment. Figure S23 shows the schematic of the cell. As shown in this figure, the cell consists of a sample holder with a current collector, a platinum wire and an $\mathrm{Ag} / \mathrm{AgCl}$ electrode that are used as the working, counter and reference electrodes, respectively. The cell has an electrolyte chamber with a volume of $4.5 \mathrm{~mL}$. The working electrode was prepared by coating $0.35 \mathrm{mg}$ of $\mathrm{OFn}-\mathrm{Cu}(5 \mathrm{~nm})$ nanoparticles on a gas diffusion layer (GDL) with an active surface area of $3.5 \mathrm{~cm}^{2}$.

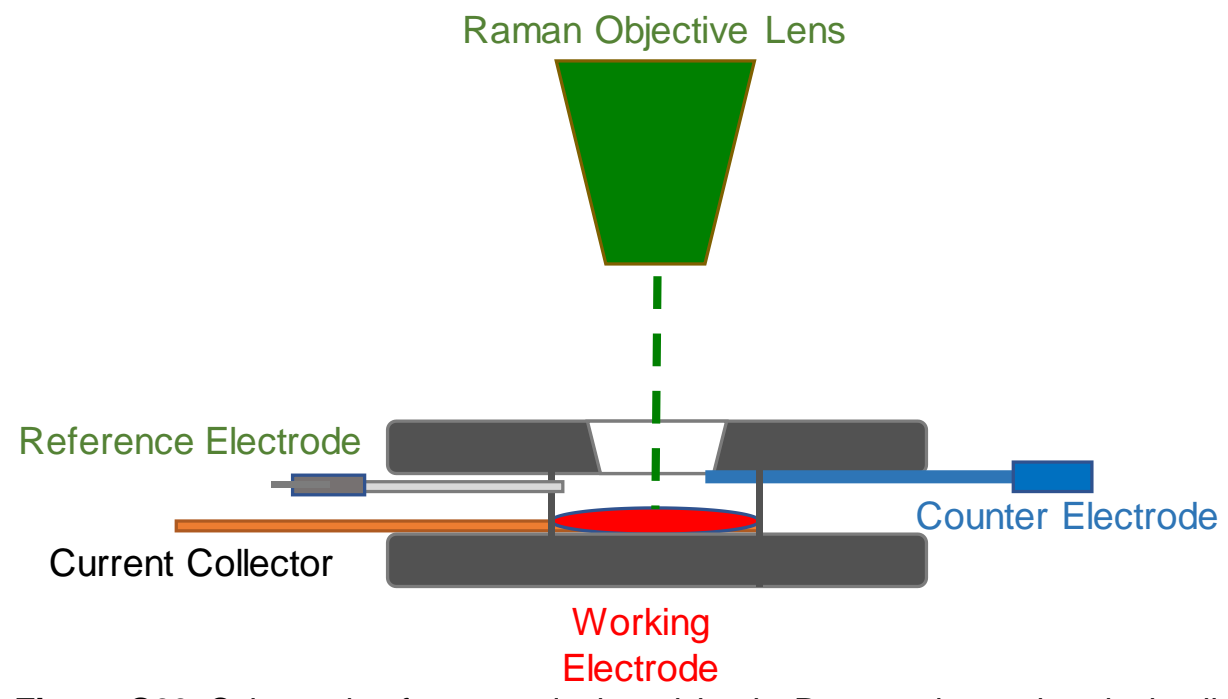

Figure S23. Schematic of custom designed in-situ Raman electrochemical cell

The in-situ Raman spectroscopy was carried out using Horiba LabRAM HR Evo Confocal Raman (Horiba scientific instrument, US). A 532 nm laser source, a HORIBA Synapse detector, $600 \mathrm{~g} / \mathrm{mm}$ grating and a long-distance $50 \mathrm{x}$ objective was used to probe the samples. The measurement parameters such as acquisition time, averaging parameters and laser power were all optimized to enhance the signal to noise ratio of the spectra. The Raman laser was focused onto the surface of the working electrode through a transparent quartz window ( $1 \mathrm{~mm}$ thick) and a thin layer of electrolyte with a total optical path of $3.25 \mathrm{~mm}$. The CA experiment was performed using OFn-Cu $(5 \mathrm{~nm})$ catalyst in a $\mathrm{CO}_{2}$ saturated $1 \mathrm{M} \mathrm{KHCO}_{3}$ solution for 1 hour. In-situ Raman analysis was conducted every 15 minutes during the CA experiment to detect any changes in the 
oxidation state of the OFn-Cu ( $5 \mathrm{~nm})$ catalyst. Figure S24b shows the recorded Raman spectra of OFn-Cu (5nm) from 100 to $700 \mathrm{~cm}^{-1}$ at different time intervals. As shown in this figure, the Raman spectrum of pristine OFn-Cu $(5 \mathrm{~nm})$ catalyst shows peaks at $213.52 \mathrm{~cm}^{-1}\left(\mathrm{Cu}_{2} \mathrm{O}\right), 295 \mathrm{~cm}^{-}$ ${ }^{1}(\mathrm{CuO}), 341.77 \mathrm{~cm}^{-1}(\mathrm{CuO})$ and $631.08 \mathrm{~cm}^{-1}(\mathrm{CuO})$. The in-situ Raman analysis at different time intervals shown in Figure S24b does not show any shift in the observed peaks after one hour of $\mathrm{CA}$ experiment at $-1.05 \mathrm{~V}$ vs RHE, indicating that oxidation state of $\mathrm{OFn}-\mathrm{Cu}(5 \mathrm{~nm})$ catalyst remains stable and unchanged during the CA experiment.
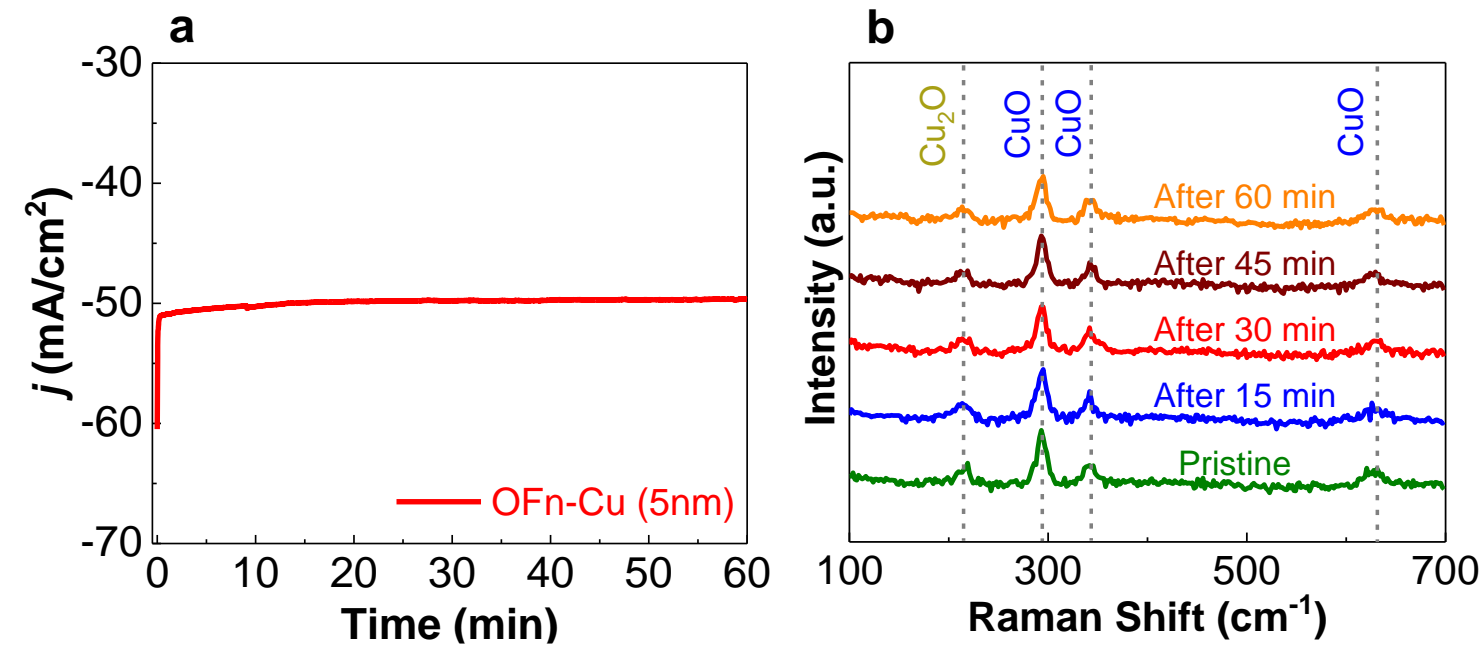

Figure S24. In-situ Raman measurement of OFn-Cu $(5 \mathrm{~nm})$ at a potential of $-1.05 \mathrm{~V}$ vs RHE in the custom designed Raman cell. (a) The current density as a function of time (b) Raman spectra of OFn-Cu $(5 \mathrm{~nm})$ during the $\mathrm{CO}_{2}$ reduction reaction at different time intervals.

Additionally, we performed the Ar etching XPS experiment on used OFn-Cu (5 nm) catalyst to compare the composition of used and fresh nanoparticles (Figure S25). The XPS depth profile of used OFn-Cu $(5 \mathrm{~nm}$ ) (The chronoamperometry experiment was performed in two-compartment three electrode electrochemical cell with a $\mathrm{CO}_{2}$ saturated $1 \mathrm{M} \mathrm{KHCO}_{3}$ at $-1.25 \mathrm{~V}$ vs $\mathrm{RHE}$ for 1 hour) indicates the weigh percentages of $\mathrm{CuO}, \mathrm{Cu}_{2} \mathrm{O}$ and $\mathrm{Cu}$ on the surface stayed fairly the same after CA experiment. 


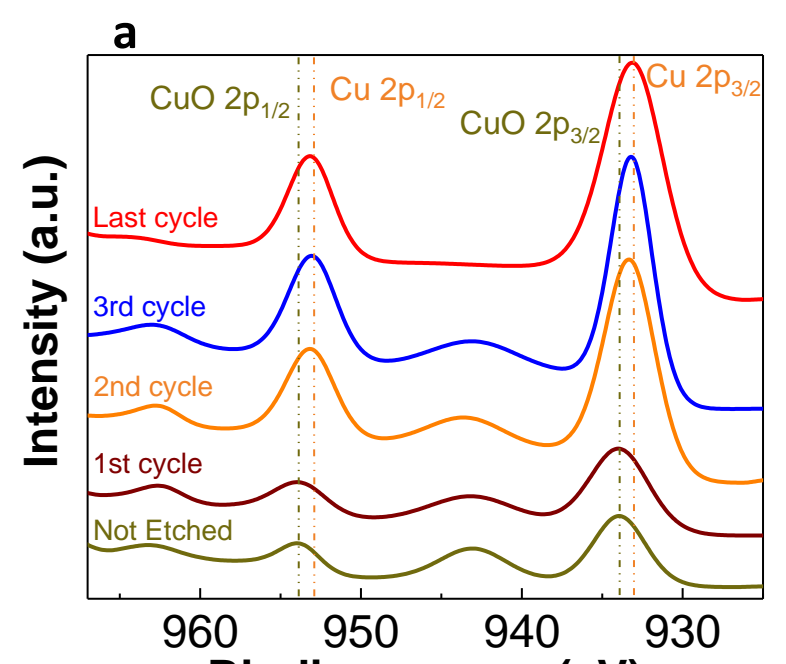

Binding energy (eV)

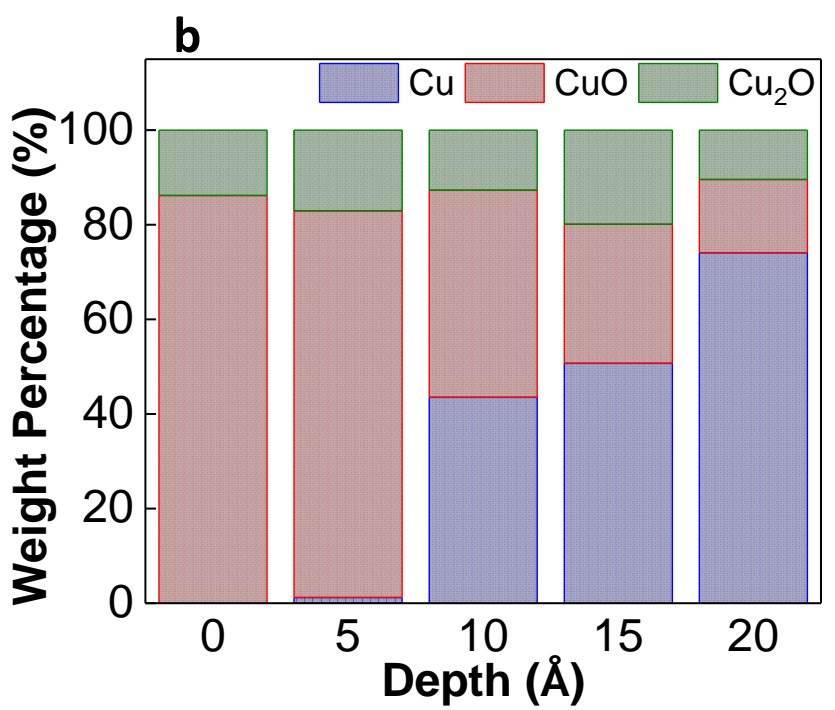

Figure S25. (a) The set of Cu spectra for used $5 \mathrm{~nm}$ OFn-Cu measured during a depth profiling experiment (b) Weight percentage of Cu compositions for used OFn-Cu $(5 \mathrm{~nm})$ at different etching cycles

\section{S12- Scanning electron microscopy (SEM) images of fresh and used electrodes}

We have performed scanning electron microscopy (SEM) on the fresh and used samples after electrochemical $\mathrm{CO}_{2}$ reduction reaction. The SEM imaging of the used sample has been performed after CA experiment at a potential of $-1.05 \mathrm{~V}$ vs RHE for 60 min (Figure S26). Both fresh and used samples were immediately transferred and stored in the Ar filled glovebox to avoid any contamination/oxidations. Samples were then sealed in a custom-made sample holder for further SEM experiments.

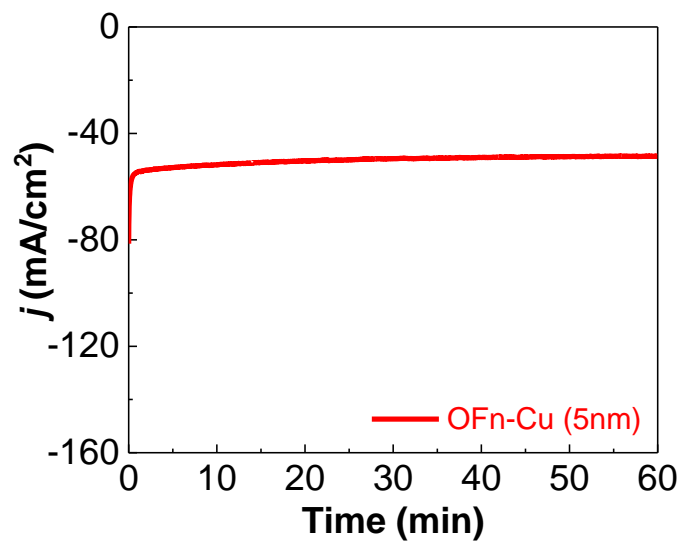

Figure S26. Chronoamperometry $(\mathrm{CA})$ result of $\mathrm{OFn}-\mathrm{Cu}(5 \mathrm{~nm})$ in three electrode electrochemical cell. The experiment was performed using $\mathrm{CO}_{2}$ saturated $1 \mathrm{M} \mathrm{KHCO}_{3}$ electrolyte for 60 min. 
The surface morphologies were analyzed using a scanning electron microscope Hitachi S4700 SEM at the center for Nanoscale Materials (CNM) in Argonne National Laboratory (ANL). Before inserting the specimen into the Specimen Exchange Chamber (SEC) of the instrument, its pressure (SEC Pi value) was dropped by less than $3 \mathrm{~Pa}$. Then, the values of $\mathrm{l}_{\mathrm{e}}$ was set to $10 \mu \mathrm{A}$ using the High-Voltage (HV) Control dialog box. As for the column operating conditions, the SEM images were obtained in the Analysis operation mode. To do so, the condenser lens value (Cond Lens 1) and working distance (WD) for the objective lens were set as " 5 " and $12 \mathrm{~mm}$, respectively, to optimize the probe sizes, beam-current, signal-to-noise ratio, resolution, depth of focus, and the specimen tilt range. Secondary Electron (SE) Detector was also selected as Mix (upper and lower added). Figure S27a, b and c, d show the collected SEM images at an accelerating voltage of $10 \mathrm{kV}$ on the sealed electrode before and after electrochemical $\mathrm{CO}_{2}$ reduction reaction, respectively, indicating a similar surface morphology before after the experiments.

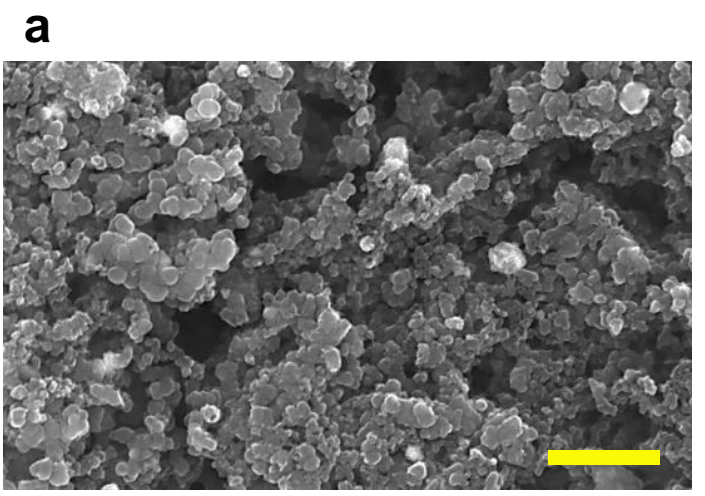

C

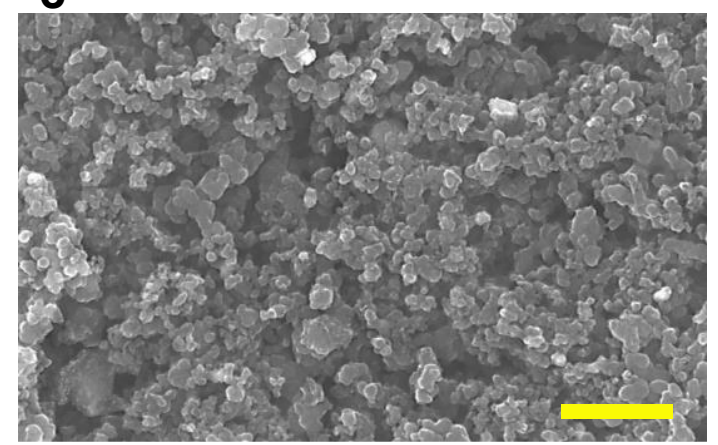

Figure S27. Scanning Electron Microscopy (SEM) images of OFn-Cu $(5 \mathrm{~nm})$ electrode $(\mathrm{a}, \mathrm{b})$ after experiment (c,d) before experiment (scale bars in both images, $500 \mathrm{~nm}$ ). b
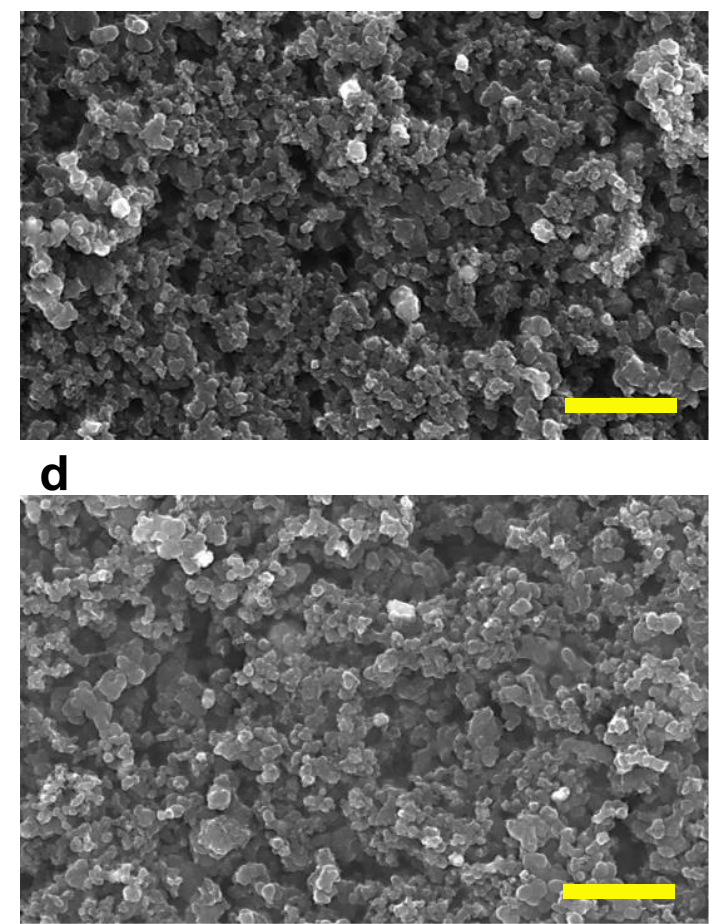


\section{S13- Work function measurements-ultraviolet photoelectron spectroscopy (UPS) Method}

To obtain more insight into the origin of this impressive $\mathrm{CO}_{2}$ reduction reaction to methane activity in the synthesized catalysts, we compared the surface work function of OFn-Cu (5 nm) nanoparticles, $\mathrm{Cu}(5 \mathrm{~nm})$ and treated $\mathrm{Cu}$ foil, which can be correlated to the surface catalytic activity of them. The surface work function measurements were carried out using a Thermo Scientific ESCALAB 250 XI photoelectron spectrometer using He I (21.2 eV) ultraviolet radiation and the pass energy of $8.95 \mathrm{eV} .{ }^{29}$ As shown in Figure S28, the results show that presence of subnanometer oxidized layer on the surface of $\mathrm{Cu}(\mathrm{OFn}-\mathrm{Cu})$ decreases the surface work function.

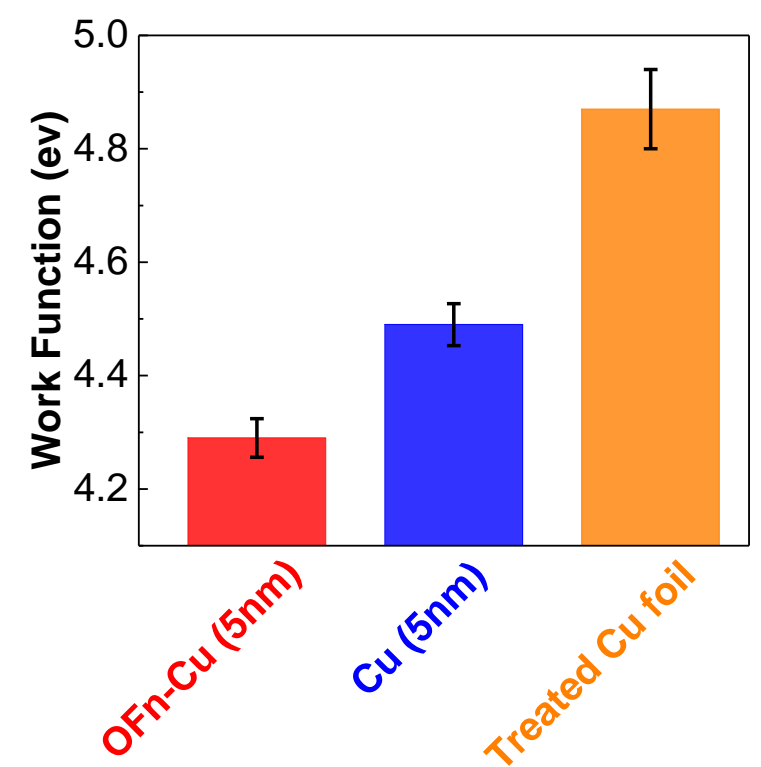

Figure S28. Work function measurements using ultraviolet photoelectron spectroscopy (UPS) for different catalysts

\section{S14- Two-compartment flow cell experiments: methods and materials}

The electrocatalytic activity of OFn-Cu $(5 \mathrm{~nm})$ as the cathode, platinum black nanoparticles as the anode and the $1 \mathrm{M} \mathrm{KHCO}_{3}$ electrolyte were studied in a custom designed two-compartment electrochemical flow cell. Figure S29 shows the schematic of the flow cell setup with total space volume of $60 \mathrm{ml}$, where two $1 \mathrm{~cm}$ thick polypropylene sheets with a $5 \mathrm{~cm} \times 5 \mathrm{~cm}$ window are placed between two gas diffusion layers GDLs and there is an ionic exchange membrane (Selemion, AGC Engineering Co.) to separate catholyte (30 $\mathrm{ml}$ volume) and anolyte (30ml 
volume). The membrane was sonicated in DI water for $30 \mathrm{~min}$ at $80^{\circ} \mathrm{C}$ and dried over $\mathrm{N}_{2}$ to clean the surface prior to use. The exposed geometric active area of the cell is $25 \mathrm{~cm}^{2}$. The electrolyte was continuously pumped through the chambers of the electrochemical flow cell with constant flow rate of $25 \mathrm{ml} / \mathrm{min}$.

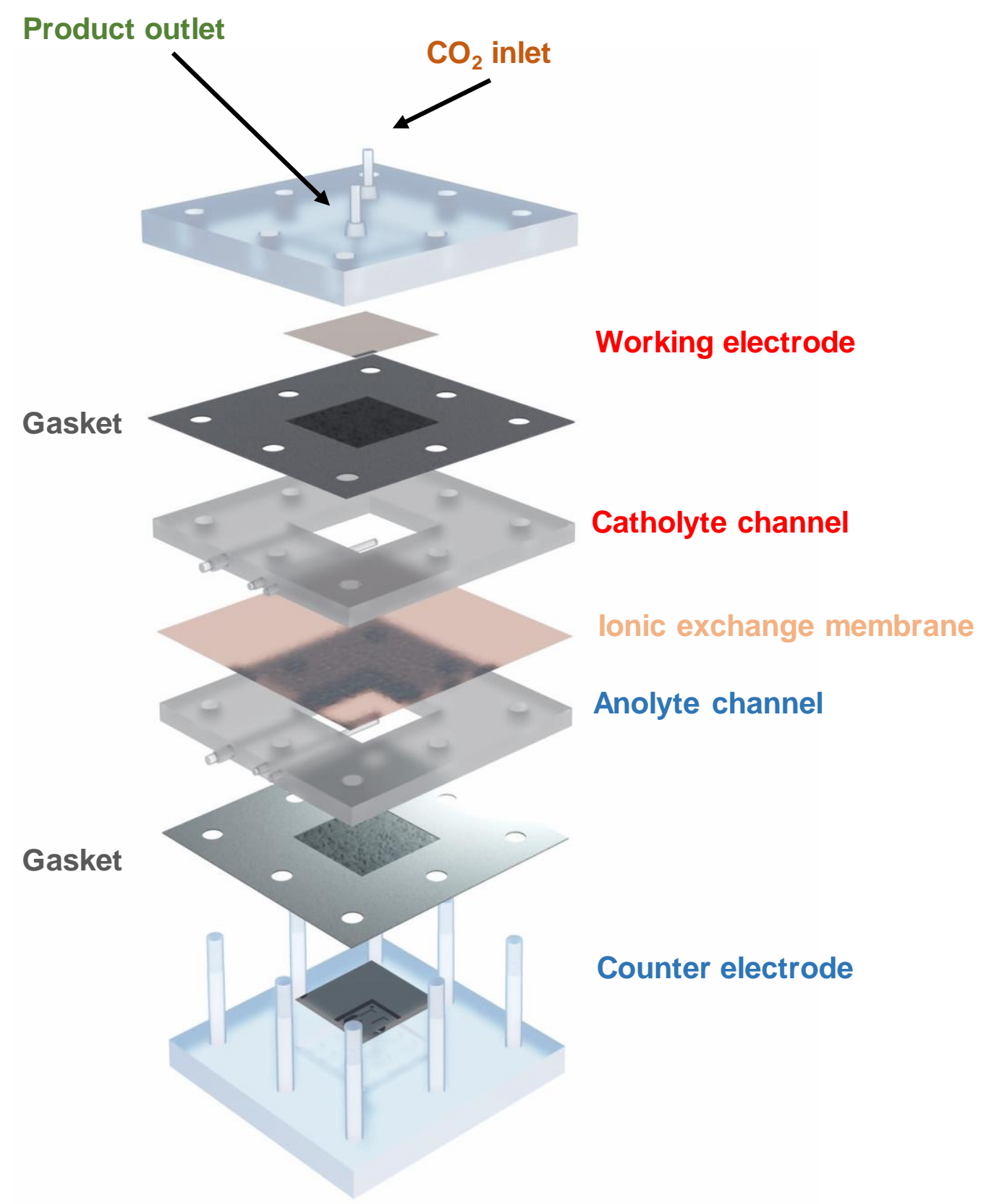

Figure S29. A schematic of two-compartment flow cell for continuous $\mathrm{CO}_{2}$ reduction reaction 
The cathode and the anode catalysts were coated on a gas diffusion electrodes (GDEs) with their respective catalysts. At first, $30 \mathrm{mg}$ of OFn-Cu $(5 \mathrm{~nm})$ catalyst was mixed in a solution of 10 $\mathrm{ml}$ isopropanol. The solution was then sonicated for 30 minutes before being applied into an area of $25 \mathrm{~cm}^{2}$ on the GDE using a paintbrush. The same procedure was used for the anode catalyst, except that $30 \mathrm{mg}$ of Pt black nanoparticles (50 nm, Alfa Aesar) were utilized in place of the OFn$\mathrm{Cu}(5 \mathrm{~nm})$. The cathode and anode were in contact with their respective aluminum mesh current collectors. A gas flow controller (Sierra Instrument, model SmartTrack 50, calibrated with $\mathrm{CO}_{2}$ gas) connected to the top gas channel through a $2 \mathrm{~mm}$ diameter tube, was used to supply the $\mathrm{CO}_{2}$ at $30 \mathrm{sccm}$ flow rate.

The CA experiments were used to study the performance of the flow cell reactor by applying different cell potentials (potential difference between cathode and anode) and reading the current at the same time. The cathode potentials were also monitored during the experiment. The CA results of the flow cell at different cell potentials $(-1.5$ to $-2.5 \mathrm{~V})$ are presented in Figure S30.

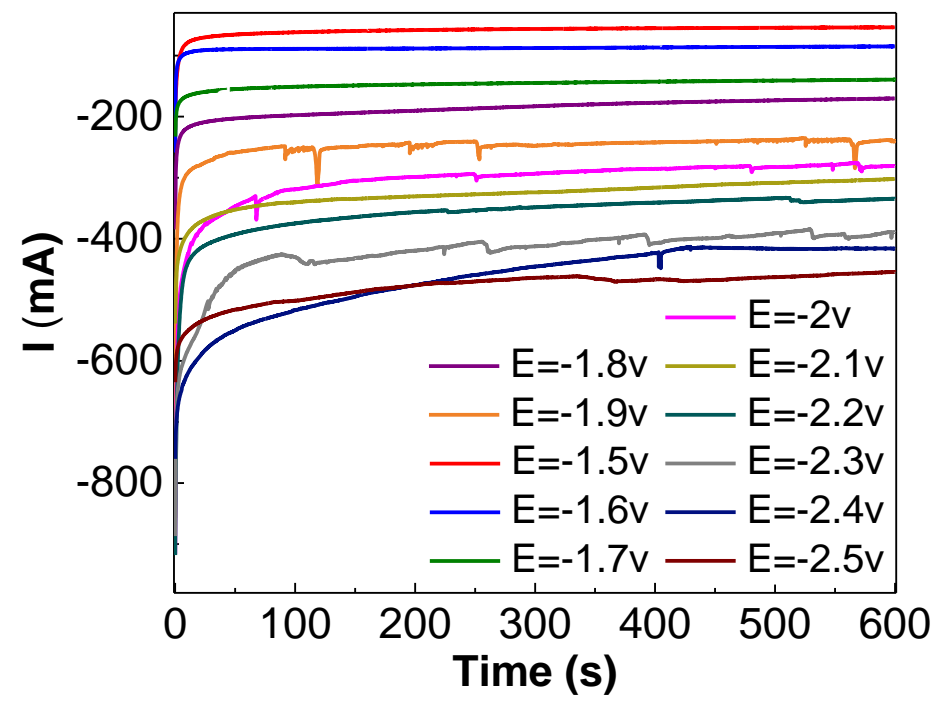

Figure S30. Chronoamperometry results of OFn-Cu $(5 \mathrm{~nm})$ in two-compartment flow cell at different applied cell potentials are measured in $\mathrm{CO}_{2}$ saturated $1 \mathrm{M} \mathrm{KHCO}_{3}$

Figure S31 indicates the faradaic efficiency (FE) measurements of OFn-Cu $(5 \mathrm{~nm})$ catalyst at different cell potentials from -1.5 to $-2.5 \mathrm{~V}$, indicating that OFn-Cu $(5 \mathrm{~nm})$ is highly selective for 
methane formation at cell potentials from -2.2 to $-2.5 \mathrm{~V}$. In addition, the maximum methane formation $\mathrm{FE}$ of $61.4 \%$ was obtained at the cell potential of $-2.5 \mathrm{~V}$. At lower cell potentials from -2 to $-2.2 \mathrm{~V}, \mathrm{OFn}-\mathrm{Cu}(5 \mathrm{~nm})$ is a highly $\mathrm{CO}$ selective catalyst, showing a maximum $\mathrm{CO}$ formation FE of $25.34 \%$ at the cell potential of $-2.1 \mathrm{~V}$.

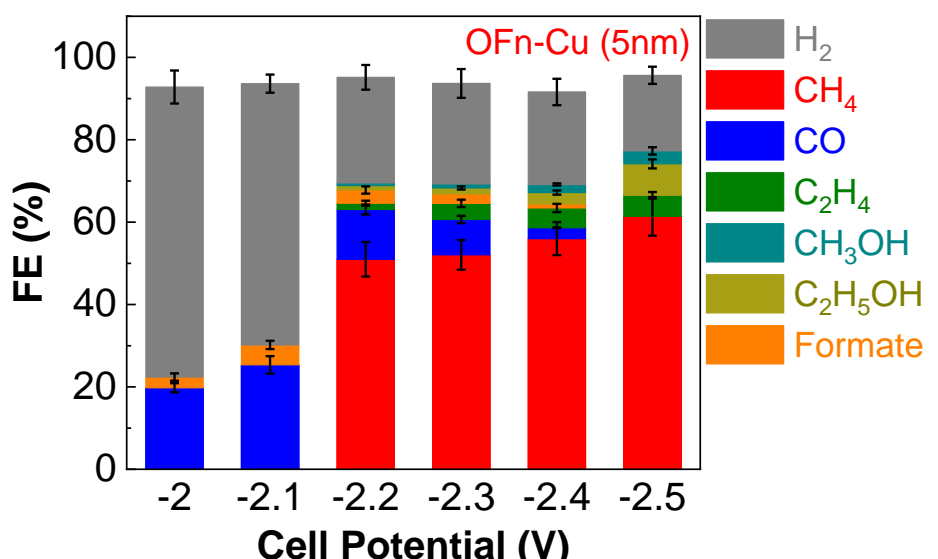

Figure S31. Faradaic efficiency measurements of $\mathrm{OFn}-\mathrm{Cu}(5 \mathrm{~nm})$ in two-compartment continuous cell

The calculated $\mathrm{CH}_{4}, \mathrm{C}_{2} \mathrm{H}_{4}$, formate, $\mathrm{CO}, \mathrm{CH}_{3} \mathrm{OH}, \mathrm{C}_{2} \mathrm{H}_{5} \mathrm{OH}$ and $\mathrm{H}_{2}$ formation TOFs are shown in Figure S32. The results indicate OFn-Cu $(5 \mathrm{~nm})$ is highly selective for methane formation at cell potentials from -2.2 to $-2.5 \mathrm{~V}$, as confirmed by faradaic efficiency results. In addition, the maximum methane formation TOF of $0.0258 \mathrm{~S}^{-1}$ was obtained at the cell potential of $-2.5 \mathrm{~V}$. At lower cell potentials from -2 to $-2.2 \mathrm{~V}, \mathrm{OFn}-\mathrm{Cu}(5 \mathrm{~nm})$ is selective for $\mathrm{CO}$, showing a maximum $\mathrm{CO}$ formation TOF of $0.0283 \mathrm{~S}^{-1}$ at the cell potential of $-2.1 \mathrm{~V}$. As shown in Figure S32, the maximum $\mathrm{H}_{2}$ formation TOF of $0.07318 \mathrm{~S}^{-1}$ is achieved at cell potential of $-2 \mathrm{~V}$. Moreover, the maximum $\mathrm{C}_{2} \mathrm{H}_{4}$ and formate formation TOF of 0.001428 and $0.003801 \mathrm{~S}^{-1}$ are achieved at cell potentials of -2.5 and $-2.1 \mathrm{~V}$, respectively. Maximum $\mathrm{CH}_{3} \mathrm{OH}$ and $\mathrm{C}_{2} \mathrm{H}_{5} \mathrm{OH}$ formation TOF of 0.001762 and $0.002141 \mathrm{~S}^{-1}$ were obtained at cell potential of $2.5 \mathrm{~V}$. 

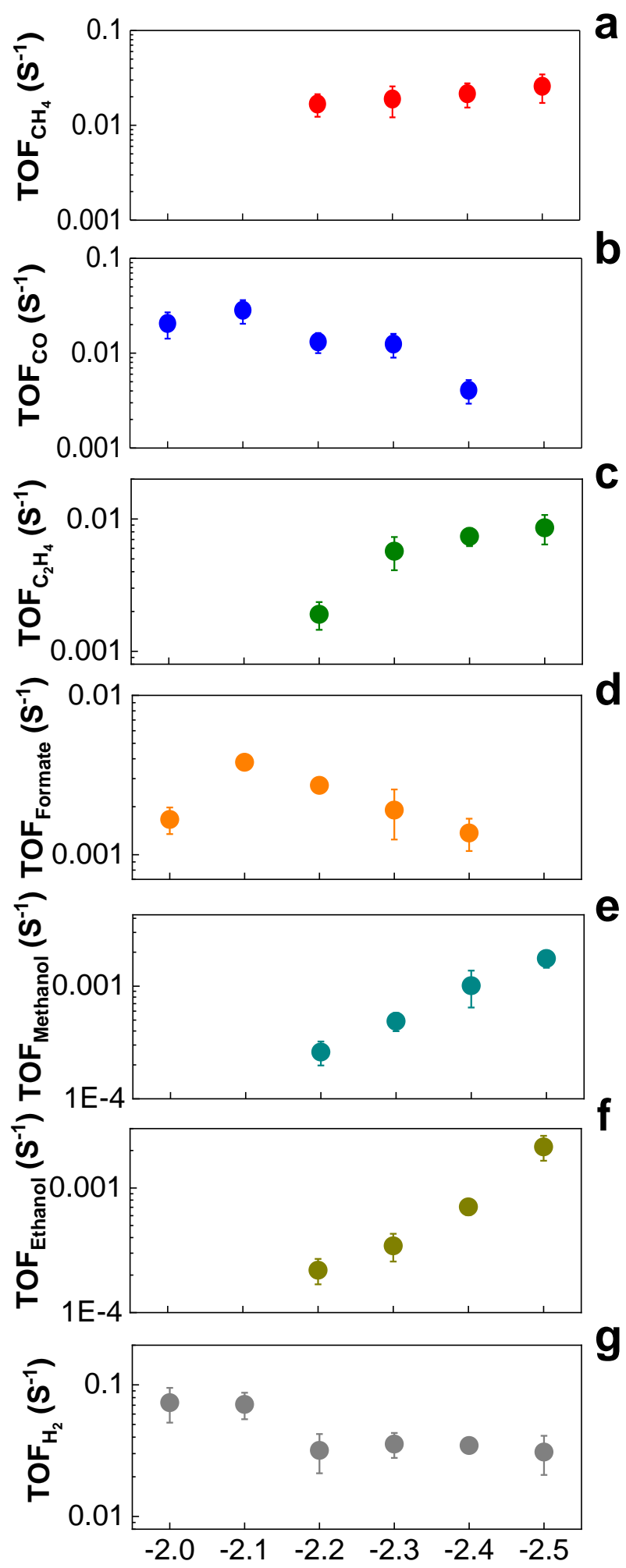

Cell Potential (V)

Figure S32. Turnover frequency measurements of $\mathrm{OFn}-\mathrm{Cu}(5 \mathrm{~nm})$ in the two-compartment flow cell for formation of (a) $\mathrm{CH}_{4}$ (b) $\mathrm{CO}$ (c) $\mathrm{C}_{2} \mathrm{H}_{4}$ (d) formate (e) $\mathrm{CH}_{3} \mathrm{OH}$ (f) $\mathrm{C}_{2} \mathrm{H}_{5} \mathrm{OH}$ and (g) $\mathrm{H}_{2}$ products. 
Figure S33 exhibits the total energy efficiency measurements for the OFn-Cu $(5 \mathrm{~nm})$. The results indicate the maximum efficiency of $62.5 \%$ at $-2.0 \mathrm{~V}$ cell potential, when having both methane and carbon monoxide products. However, at $-2.2 \mathrm{~V}$ cell potential, the total system efficiency is about $49.8 \%$.

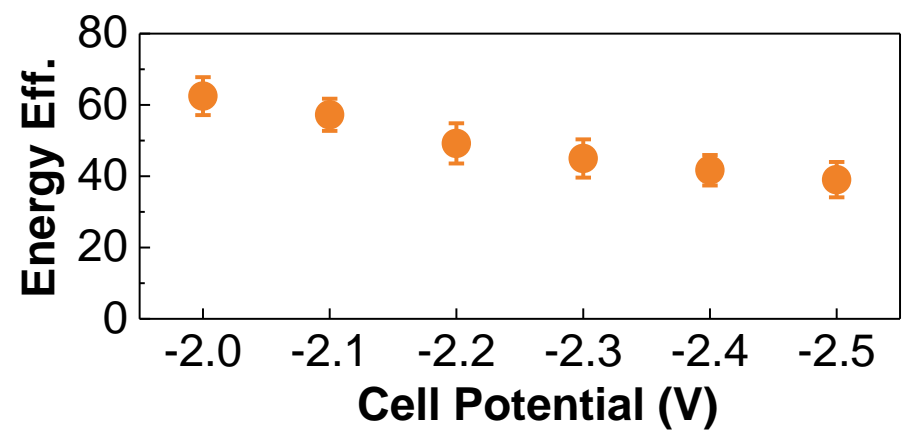

Figure S33. Total energy efficiency measurements of OFn-Cu $(5 \mathrm{~nm})$ in two-compartment flow cell (with $25 \mathrm{~cm}^{2}$ active area) at different cell potentials.

\section{S15- Electrochemical performance of the solar-powered flow cell}

\section{S15.1- Methods and Materials}

For the standalone self-operating process, the two-compartment electrochemical flow cell was connected to a triple junction photovoltaic (TJ-PV) solar cell to power the flow cell with solar energy. Figure S34 shows the schematic of solar-powered two-compartment electrochemical flow cell. A sun simulator light source was used to provide different sun illumination energies for the TJ-PV cell. Therefore, a preliminary procedure was used to calibrate different sun illumination distances. An InGaAs photodiode (Thorlabs, FDG03-CAL) with a known responsivity calibration curve was used to measure $0.5,1,1.5$ and 2 sun illuminations energies. The TJ-PV cell was characterized by connecting the PV cell to the potentiostat. 


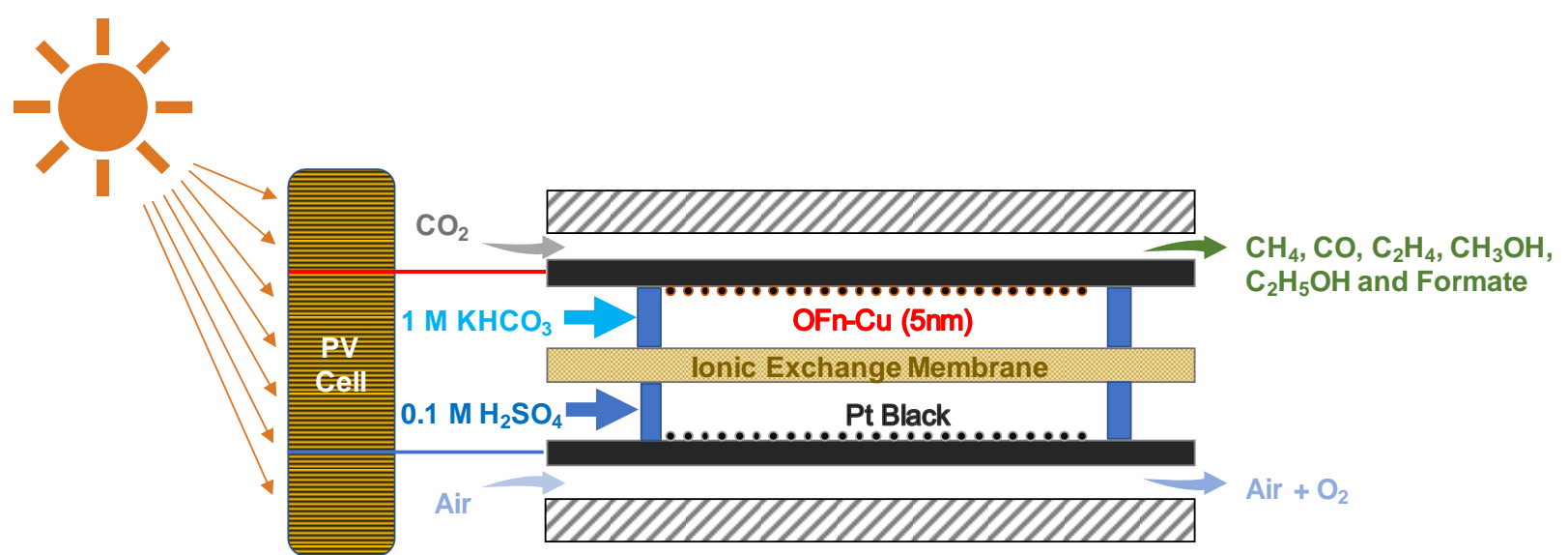

Figure S34. A schematic of two-compartment flow cell using solar energy for electrochemical conversion of $\mathrm{CO}_{2}$ to $\mathrm{CH}_{4}$

Figure S35 shows j-V curves of the cell obtained at different sun illuminations. The efficiency of TJ-PV cell refers to the ability of solar panel to convert sunlight into electrical energy calculating by Equation $\mathrm{S} 8$ where the $P_{S}$ and $P_{m p}$ are the power of sunlight that hits the solar cell's surface $\left(1 \mathrm{KW} / \mathrm{m}^{2}\right)$ and maximum power of solar cell, respectively.

$$
\text { Maximum TJ }-P V \text { cell efficiency }=\frac{P_{m p}}{P_{s}} \times 100=\frac{V_{m p} \times I_{m p}}{P_{s}} \times 100 \quad \text { (Equation S8) }
$$

The results show that at one sun illumination the TJ-PV cell generates a photocurrent of -13.63 $\mathrm{mA} / \mathrm{cm}^{2}$, suggesting a maximum efficiency of $34.32 \%$.

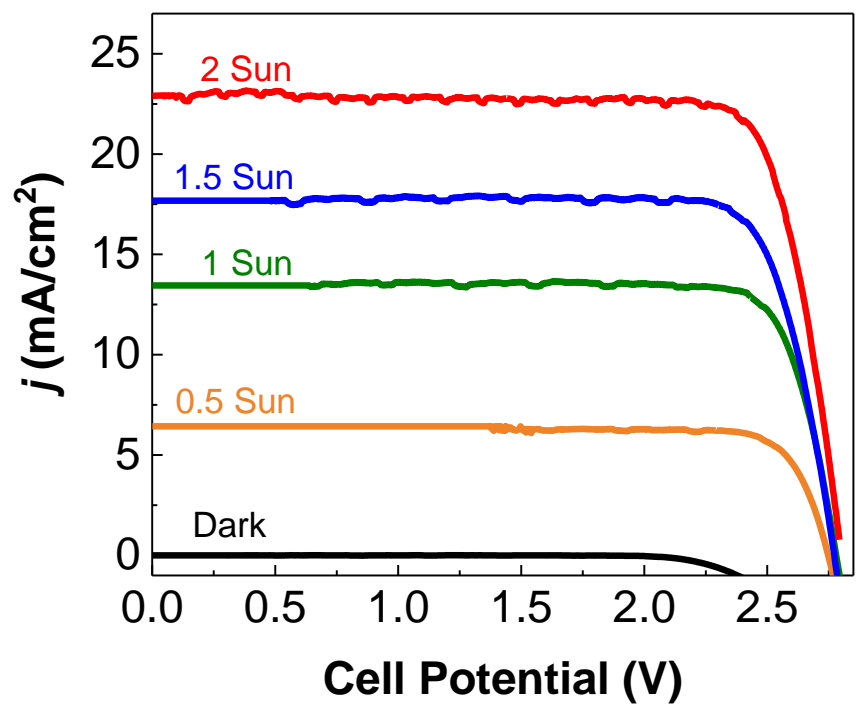

Figure S35. PV cell characterization at different sun illuminations 
The sun to $\mathrm{CH}_{4}$ and $\mathrm{CO}$ efficiency of coupled cell is calculated by using Equation S9 (Figure 4b, main text). ${ }^{30,31}$

$$
\begin{gathered}
\text { Sun to } \mathrm{CH}_{4} \text { and } \mathrm{CO}=\mathrm{TJ}-\mathrm{PV} \text { cell efficiency at operating point }\left(\mathrm{I}_{o p} \times V_{o p}\right) \times \\
\text { flow cell efficiency of } \mathrm{CH}_{4} \text { and } \mathrm{CO} \quad \text { (Equation S9) }
\end{gathered}
$$

Where the TJ-PV cell efficiency is $29.5 \%$ and the flow cell efficiency $\mathrm{CH}_{4}$ and $\mathrm{CO}$ is calculated by using Equation S10 as follow:

Flow cell efficiency $=\frac{\text { FE of product } \times \text { the product formation equilibrium potential }(V)}{\operatorname{cell} \text { potential }(V)}($ Equation $\mathrm{S} 10)$

Equilibrium potentials for $\mathrm{CH}_{4}$ and $\mathrm{CO}$ formation are $1.059 \mathrm{~V}$ and $1.329 \mathrm{~V}$, respectively. ${ }^{32}$ In addition, solar to fuel efficiency (SFE) is calculated by the sum of the sun to $\mathrm{CH}_{4}$ and the sun of CO efficiency at different cell potentials (Figure 4, main text).

Solar to fuel ef ficiency $(S F E)=$

Sum of sun to CO2RR products formation efficiency (Equation S11)

Figure S36 show sun to $\mathrm{C}_{2} \mathrm{H}_{4}$, formate, $\mathrm{CH}_{3} \mathrm{OH}, \mathrm{C}_{2} \mathrm{H}_{5} \mathrm{OH}$ and $\mathrm{H}_{2}$ formation efficiencies at different cell power densities. 

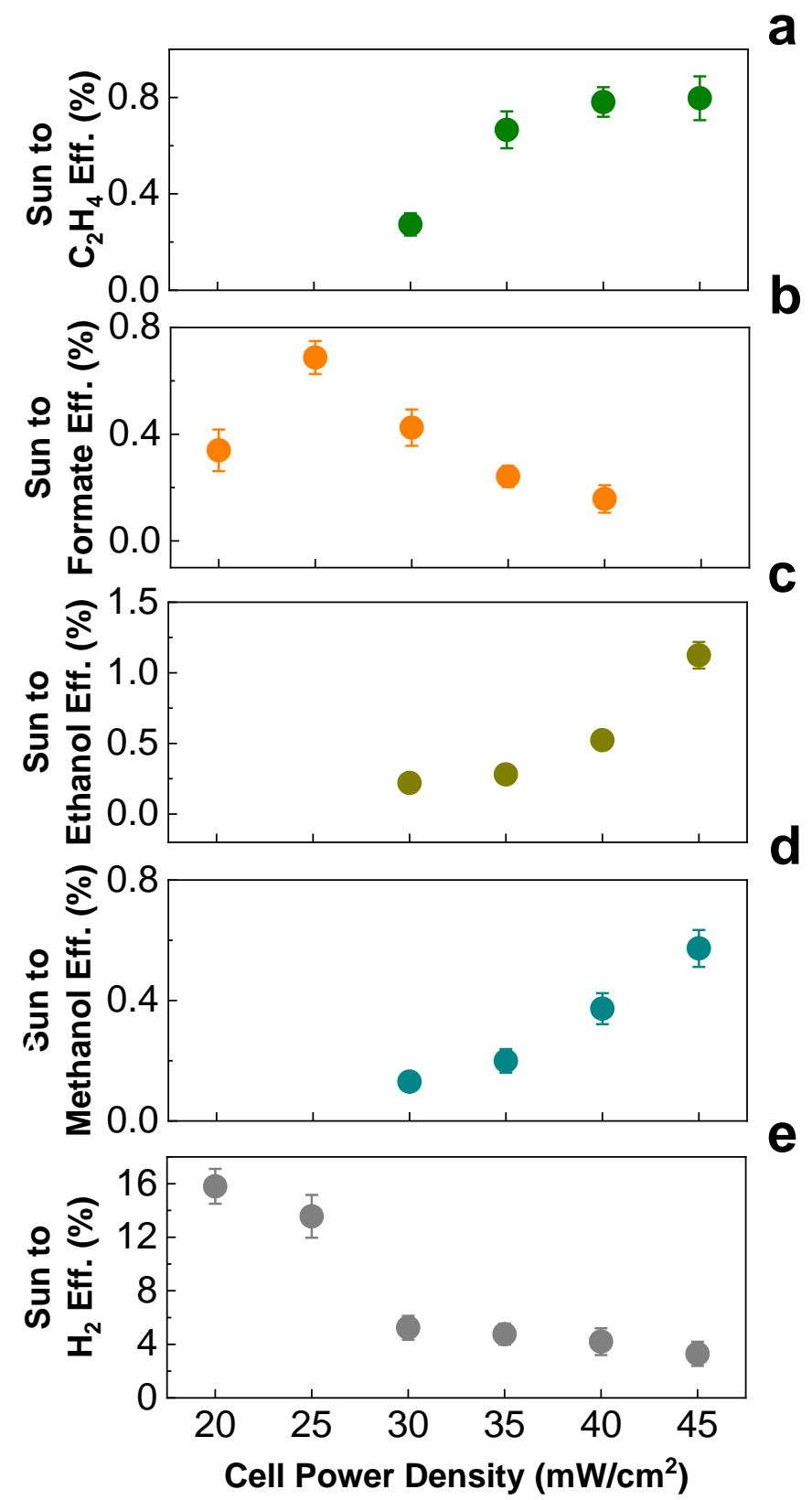

Figure S36. Sun to product formation efficiency measurements of OFn-Cu $(5 \mathrm{~nm})$ in the coupled flow cell for (a) $\mathrm{C}_{2} \mathrm{H}_{4}$ (b) formate (c) $\mathrm{C}_{2} \mathrm{H}_{5} \mathrm{OH}$ (d) $\mathrm{CH}_{3} \mathrm{OH}$ (e) $\mathrm{H}_{2}$ products

\section{S15.2- Uncertainty analysis of the Solar to Fuel Efficiency calculation}

Uncertainty analysis was performed to determine the sensitivity of the calculated SFE with respect to different parameters such as the $\mathrm{CH}_{4}$ and $\mathrm{CO}$ formation $\mathrm{F} . \mathrm{E}$, the applied potential, and the efficiency of the TJ-PV cell. A partial derivative method was employed to approximate the uncertainty of the calculations done in the Equations S8-10. In this regard, the typical value of each parameter $\left(x_{i}\right)$ is slightly varied $\left(\partial x_{i}\right)$ and the SFE values $(\partial \eta)$ were recalculated with 
respect to the changes made in the value of the corresponding parameter $(i)$. The dimensionless sensitivity, $\left(S_{i}\right)$, is then calculated to determine the overall uncertainty $\left(u_{\eta}\right)$ using Equations $S 12$ and $\mathrm{S} 13$, respectively.

$$
\begin{gathered}
\mathrm{S}_{\mathrm{i}}=\frac{\mathrm{x}_{\mathrm{i}} \partial \eta}{\eta \partial \mathrm{x}_{\mathrm{i}}} \quad(\text { Equation } \mathrm{S} 12) \\
\frac{\mathrm{u}_{\eta}}{\eta}=\sqrt{\sum_{\mathrm{i}}\left(\mathrm{s}_{\mathrm{i}} \times \frac{\mathrm{u}_{\mathrm{x}_{\mathrm{i}}}}{\mathrm{x}_{\mathrm{i}}}\right)^{2}} \quad \text { (Equation S13) }
\end{gathered}
$$

where $\left(u_{x_{i}}\right)$ is the overall uncertainty of the parameter $(i)$ around its typical value $\left(x_{i}\right), s_{i}$ is the sensitivity to that parameter $(i)$ and $\eta$ is the value of SFE. The overall uncertainty of the SFE with respect to the $\mathrm{CO}$ and $\mathrm{CH}_{4}$ formation $\mathrm{FE}$ was calculated using the standard deviation of three experiments that are 0.075 and 0.084 , respectively. Moreover, the overall uncertainty for the SFE with respect to the TJ-PV cell efficiency was calculated based on the fluctuation in the response of the photodiode during the measurement. As shown in Table S6, the sensitivity value of $\mathrm{CH}_{4}$ formation FE, CO formation FE are 0.88469 and 0.84590 , respectively. However, the equilibrium potential for formation of $\mathrm{CH}_{4}$ and $\mathrm{CO}$ are fixed values that are extracted from the literature. Therefore, $\left(\frac{u_{x_{i}}}{x_{i}}\right)$ for these two values are considered as zero.

Table S6. The summery of uncertainty analysis in the SFE calculation for one sun illumination

\begin{tabular}{cccccc}
\hline Input & $x_{i}$ (values) & $\frac{u_{x_{i}}}{x_{i}}$ & Sensitivity & $C_{i}=\left|S_{i}\right| \times \frac{u_{x_{i}}}{x_{i}}$ & $\left(c_{i}\right)^{2} / \sum\left(c_{i}\right)^{2}$ \\
\hline FE of $\mathrm{CH}_{4}$ & $50.98966(\%)$ & 0.084 & 0.884689401 & 0.07431391 & 0.005522557 \\
FE of CO & $12.08154(\%)$ & 0.075 & 0.845897309 & 0.063442298 & 0.004024925 \\
E $^{0} \mathrm{CH} 4$ & $1.059(\mathrm{~V})$ & 0 & 85.19360108 & 0 & 0 \\
E $^{0} \mathrm{co}$ & $1.329(\mathrm{~V})$ & 0 & 15.37959694 & 0 & 0 \\
PV Cell Efficiency & $29.5(\%)$ & 0.035 & 1.875584879 & 0.065645471 & 0.004309328
\end{tabular}




\section{S15.3- Stability analysis of the solar-powered flow cell}

We evaluated the long-term performance of OFn-Cu $(5 \mathrm{~nm})$ in the solar-powered flow cell by measuring SFE of the cell in a 10 hours experiment. Figure S37a shows the amount of solar to methane efficiency during a $10 \mathrm{hr}$ operating time. As shown in Figure S37b, the electrocatalytic $\mathrm{CO}_{2}$ reduction reaction starts with a current density of $-389.2 \mathrm{~mA}$ and decays to $-359.4 \mathrm{~mA}$, indicating less than $7.7 \%$ loss in the current density during $10 \mathrm{hrs}$ of the process. Also, the cumulative product formation for $\mathrm{CH}_{4}$ and $\mathrm{CO}$ during the continuous processing the $\mathrm{CO}_{2}$ is shown in Figure 3d, main text. After 10 hrs of continuous process at the optimal operating power of 30 $\mathrm{mW} / \mathrm{cm}^{2}$, approximately $7.24 \mathrm{~L}$ of $\mathrm{CH}_{4}$ is produced. whereas the corresponding value for $\mathrm{CO}$ is $1.78 \mathrm{~L}$ (Figure 3d).

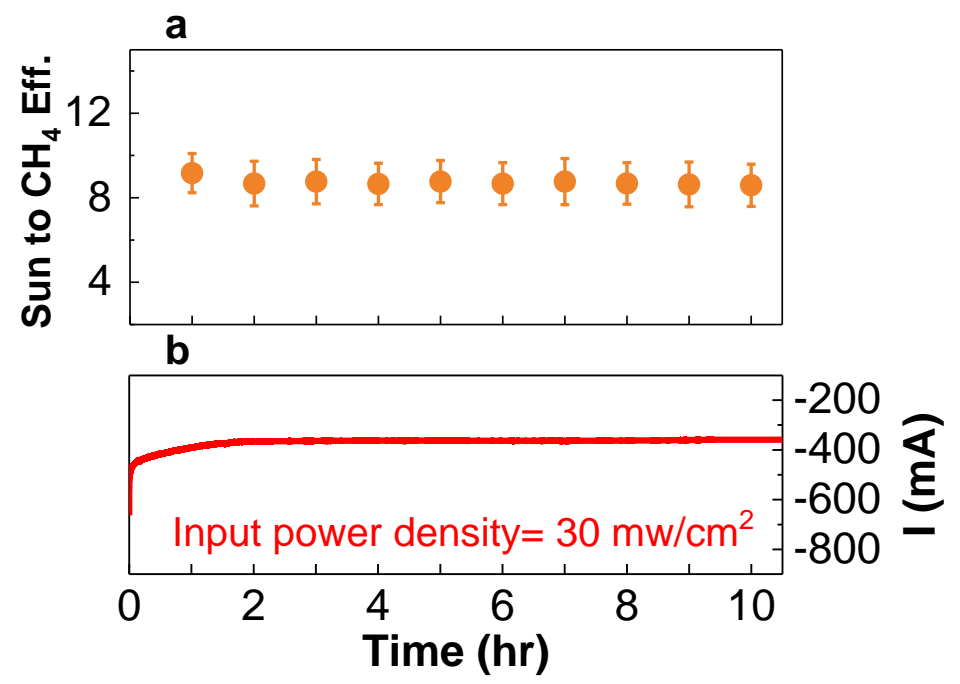

Figure S37. Long-term performance of solar-powered two-compartment flow cell with $25 \mathrm{~cm}^{2}$ active area. (a) solar to $\mathrm{CH}_{4}$ formation efficiency. (b) Chronoamperometry (CA) experiment at $30 \mathrm{~mW} / \mathrm{cm}^{2} \mathrm{implying}$ less than $7.7 \%$ current density loss after $10 \mathrm{hrs}$ of continuous reduction of $\mathrm{CO}_{2}$.

\section{S16- Computational methods}

First-principles calculations were performed using the projector augmented-wave (PAW) method as implemented in the Vienna ab initio Simulation Package (VASP). ${ }^{33}$ The exchangecorrelation energy was approximated using the generalized gradient approximation (GGA) with the Perdew-Burke-Ernzerhof (PBE) parameterization. ${ }^{34}$ The optimized bulk CuO structure was 
retrieved from the Materials Project. ${ }^{35}$ Surface energy and work function were then calculated for low-index surfaces of $\mathrm{CuO} .{ }^{36}$ The slab models for these surfaces contain at least $15 \AA$ of atomic layers and vacuum spacing, where all layers could relax during the surface-energy calculations. Adsorption of selected $\mathrm{C}_{1}$ products $(\mathrm{CO}, \mathrm{CHO}, \mathrm{COH}$, and $\mathrm{COOH})$ was calculated on the $\mathrm{CuO}$ (101) surface, the lowest-energy surface termination studied. The $\mathrm{CuO}$ (101) slab was composed of nine layers of four $\mathrm{Cu}$ and $\mathrm{O}$ atoms. The adsorption was considered at both the $\mathrm{Cu}$ and $\mathrm{O}$ site of the $\mathrm{CuO}$ (101) surface to study the preferred adsorption site at the $1 / 4 \mathrm{ML}$ coverage (in terms of surface $\mathrm{Cu}$ atoms). Figure $\mathrm{S} 38$ indicates the side view and the top view of $\mathrm{CuO}$ (101) surface.

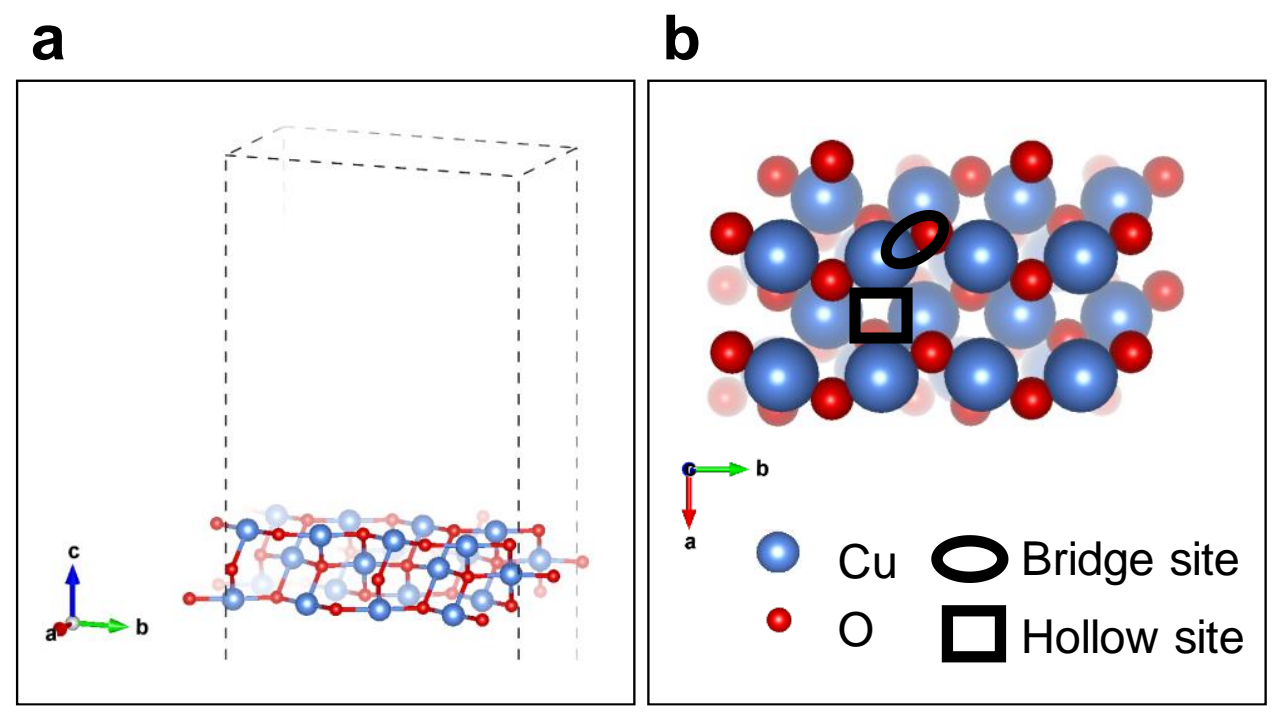

Figure S38. (a) Side view, (b) top view of the $\mathrm{CuO}$ (101) surface. The larger blue balls represent $\mathrm{Cu}$ atoms and smaller red balls represent $\mathrm{O}$ atoms. The bridge and hollow site are highlighted by green circle and square.

During the adsorption calculations, the top three atomic layers and adsorption products could relax. All calculations were initialized with high spin-polarization and the cutoff energy for the planewave expansion was $520 \mathrm{eV}$. A $2 \times 2 \times 1$ gamma-centered k-point mesh was used for slab calculations. The energy and force criteria for slab relaxation were $1 \times 10^{-3} \mathrm{eV} /$ atom and $0.02 \mathrm{eV} /$ $\AA$. The equilibrium morphology of $\mathrm{CuO}$ particles is predicted by constructing a Wulff shape with the surface energy values in Table S7. The prevailing surfaces of the Wulff shape are the (101) 
surface, which constitutes $27 \%$ of the particle surface area, and followed by the (101) surface at $26 \%$.

Table S7. Surface energy and work function for low-index surface terminations of CuO

\begin{tabular}{ccc}
\hline Surface termination & Surface energy $(\mathrm{eV} / \AA)$ & Work function $(\mathrm{eV})$ \\
\hline 001 & 0.262 & 7.544 \\
$010(1)$ & 0.203 & 6.049 \\
$010(2)$ & 0.237 & 6.423 \\
100 & 0.247 & 6.624 \\
$110(1)$ & 0.212 & 5.627 \\
$110(2)$ & 0.234 & 6.618 \\
101 & 0.179 & 5.268 \\
$011(1)$ & 0.308 & 6.830 \\
$011(2)$ & 0.251 & 5.071 \\
$10 \overline{1}$ & 0.184 & 5.152 \\
$111(1)$ & 0.286 & 7.220 \\
$111(2)$ & 0.195 & 5.647 \\
$11 \overline{1}$ & 0.278 & 5.691
\end{tabular}

The adsorption energy of $\mathrm{C}_{1}$ products is calculated as:

$$
E_{\text {adsorption }}=E_{\text {slab with adsorbate }}-E_{\text {clean slab }}-E_{\text {adsorbate }} \text { (Equation S14) }
$$

where $E_{\text {slab with adsorbate, }} E_{\text {clean slab }}$, and $E_{\text {adsorbate }}$ are the total energies of the adsorbed CuO (101) surface, clean $\mathrm{CuO}$ (101) surface, and adsorbate in a box, respectively (Table S8).

Table S8. Adsorption energy of $\mathrm{CO}, \mathrm{CHO}, \mathrm{COH}$, and $\mathrm{COOH}$ on the $\mathrm{Cu}(101)$ surface. *

\begin{tabular}{l|cc|cc|lc|ll}
\hline \multicolumn{3}{c}{} & \multicolumn{2}{c}{$\mathrm{CO}$} & \multicolumn{2}{c}{$\mathrm{COH}$} & \multicolumn{2}{c}{$\mathrm{COOH}$} \\
\hline \multirow{3}{*}{ E $_{\text {adsorption }}$} & Cu site & O site & Cu site & O site & Cu site & O site & Cu site & O site \\
& -0.068 & -0.918 & -1.318 & -2.767 & -3.589 & -3.756 & Unstable & -2.362 \\
\hline
\end{tabular}

${ }^{*}$ The adsorption site in the table refers to the initial site for relaxation (Figures S38a and b). The final adsorption site can be slightly off the initial position as discussed in the main text. 


\section{References}

(1) Guo, L. W.; Du, P. P.; Fu, X. P.; Ma, C.; Zeng, J.; Si, R.; Huang, Y. Y.; Jia, C. J.; Zhang, Y. W.; Yan, C. H. Contributions of Distinct Gold Species to Catalytic Reactivity for Carbon Monoxide Oxidation. Nat. Commun. 2016, 7, 13481.

(2) Zhang, S.; Nguyen, L.; Liang, J.-X.; Shan, J.; Liu, J.; Frenkel, A. I.; Patlolla, A.; Huang, W.; Li, J.; Tao, F. Catalysis on Singly Dispersed Bimetallic Sites. Nat. Commun. 2015, 6, 7938.

(3) Murdoch, M.; Waterhouse, G. I. N.; Nadeem, M. A.; Metson, J. B.; Keane, M. A.; Howe, R. F.; Llorca, J.; Idriss, H. The Effect of Gold Loading and Particle Size on Photocatalytic Hydrogen Production from Ethanol over $\mathrm{Au} / \mathrm{TiO}_{2}$ Nanoparticles. Nat. Chem. 2011, 3, 489.

(4) Serpell, C. J.; Cookson, J.; Ozkaya, D.; Beer, P. D. Core@shell Bimetallic Nanoparticle Synthesis via Anion Coordination. Nat. Chem. 2011, 3, 478.

(5) Esmaeilirad, M.; Zabihi, M.; Shayegan, J.; Khorasheh, F. Oxidation of Toluene in Humid Air by Metal Oxides Supported on $\gamma$-Alumina. J. Hazard. Mater. 2017, 333, 293-307.

(6) Chem, J. M.; Sheng, Z.; Gao, H.; Bao, W.; Wang, F.; Xia, X. Synthesis of Boron Doped Graphene for Oxygen Reduction Reaction in Fuel Cells. J. Mater. Chem. 2012, 22, 390395.

(7) Chirizzi, D.; Guascito, M. R.; Filippo, E.; Malitesta, C.; Tepore, A. A Novel Nonenzymatic

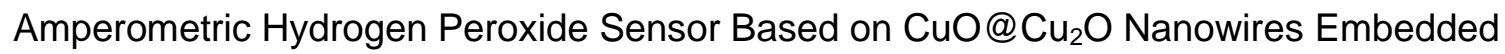
into Poly(Vinyl Alcohol). Talanta 2016, 147, 124-131.

(8) Huang, M.; Zhang, Y.; Li, F.; Wang, Z.; Alamusi; Hu, N.; Wen, Z.; Liu, Q. Merging of Kirkendall Growth and Ostwald Ripening: $\mathrm{CuO} @ \mathrm{MnO}_{2}$ Core-Shell Architectures for Asymmetric Supercapacitors. Sci. Rep. 2014, 4, 4518.

(9) Kamer, P. C. J.; Vogt, D.; Thybaut, J. W. Contemporary Catalysis: Science, Technology and Applications; Royal Society of Chemistry: Croydon, 2017.

(10) Seah, M. P.; Briggs, D. Practical Surface Analysis: Auger and X-Ray Photoelectron Spectroscopy; John Wiley: New York, 1990.

(11) Yan, Weile; Ramos, M. A. V.; Koel, B. E.; Zhang, W. Multi-Tiered Distributions of Arsenic in Iron Nanoparticles: Observation of Dual Redox Functionality Enabled by a Core-Shell 
Structure. Chem. Commun. 2010, 46, 6995-6997.

(12) Su, D.; Xie, X.; Dou, S.; Wang, G. CuO Single Crystal with Exposed $\{001\}$ Facets - A Highly Efficient Material for Gas Sensing and Li-Ion Battery Applications. Sci. Rep. 2014, 4, 5753.

(13) Wang, Q.; Zhang, Y.; Zheng, J.; Wang, Y.; Hu, T.; Meng, C. Metal Oxide Decorated Layered Silicate Magadiite for Enhanced Properties: Insight from $\mathrm{ZnO}$ and $\mathrm{CuO}$ Decoration. Dalt. Trans. 2017, 46, 4303-4316.

(14) Zhang, Y. X.; Kuang, M.; Wang, J. J. Mesoporous CuO-NiO Micropolyhedrons: Facile Synthesis, Morphological Evolution and Pseudocapcitive Performance. CrystEngComm 2014, 16, 492-498.

(15) Asadi, M.; Kim, K.; Liu, C.; Addepalli, A. V.; Abbasi, P.; Yasaei, P.; Phillips, P.; Behranginia, A.; Cerrato, J. M.; Haasch, R.; Zapol, P.; Kumar, B.; Klie, R. F.; Abiade, J.; Curtiss, L. A.; Salehi-Khojin, A. Nanostructured Transition Metal Dichalcogenide Electrocatalysts for $\mathrm{CO}_{2}$ Reduction in Ionic Liquid. Science 2016, 353, 467-470.

(16) Kumar, B.; Asadi, M.; Pisasale, D.; Sinha-Ray, S.; Rosen, B. A.; Haasch, R.; Abiade, J.; Yarin, A. L.; Salehi-Khojin, A. Renewable and Metal-Free Carbon Nanofibre Catalysts for Carbon Dioxide Reduction. Nat. Commun. 2013, 4, 2819.

(17) Abbasi, P.; Asadi, M.; Liu, C.; Sharifi-Asl, S.; Sayahpour, B.; Behranginia, A.; Zapol, P.; Shahbazian-Yassar, R.; Curtiss, L. A.; Salehi-Khojin, A. Tailoring the Edge Structure of Molybdenum Disulfide towards Electrocatalytic Reduction of Carbon Dioxide. ACS Nano 2016, 11, 453-460.

(18) Kondori, A.; Esmaeilirad, M.; Baskin, A.; Song, B.; Wei, J.; Chen, W.; Segre, C. U.; Shahbazian-yassar, R.; Prendergast, D. Identifying Catalytic Active Sites of Trimolybdenum Phosphide $\left(\mathrm{Mo}_{3} \mathrm{P}\right)$ for Electrochemical Hydrogen Evolution. Adv. Eng. Mater. 2019, 9, 1900516.

(19) Sahoo, S. R.; Ramacharyulu, P.; Ke, S. C. Impact of Nonideal Nanoparticles on X-Ray Photoelectron Spectroscopic Quantitation: An Investigation Using Simulation and Modeling of Gold Nanoparticles. Anal. Chem. 2018, 90, 1621-1627.

(20) Molavi, H.; Shojaei, A. Mixed-Matrix Composite Membranes Based on UiO-66-Derived MOFs for $\mathrm{CO}_{2}$ Separation. ACS Appl. Mater. Interfaces 2019, 11, 9448-9461. 
(21) Zhao, Y.; Sun, T.; Liao, W.; Wang, Y.; Yu, J.; Zhang, M.; Yu, Z.; Yang, B.; Gui, D.; Zhu, C.; Xu, J. Amphiphilic Graphene Aerogel with High Oil and Water Adsorption Capacity and High Contact Area for Interface Reaction. ACS Appl. Mater. Interfaces 2019, 11, 22794-22800.

(22) Kropf, A. J.; Katsoudas, J.; Chattopadhyay, S.; Shibata, T.; Lang, E. A.; Zyryanov, V.; Ravel, B.; Mclvor, K.; Kemner, K. M.; Scheckel, K. G.; Bare, S. R.; Terry, J.; Kelly, S. D.; Bunker, B. A.; Segre, C. U. The New MRCAT (Sector 10) Bending Magnet Beamline at the Advanced Photon Source. AIP Conf. Proc. 2010, 1234, 299-302.

(23) Ravel, B.; Newville, M. ATHENA, ARTEMIS, HEPHAESTUS: Data Analysis for X-Ray Absorption Spectroscopy Using IFEFFIT. J. Synchrotron Rad. 2005, 12, 537-541.

(24) Newville, M. IFEFFIT: Interactive XAFS analysis FEFF Fitting. J. Synchrotron Rad. 2001, 8, 322-324.

(25) Asadi, M.; Kumar, B.; Liu, C.; Phillips, P.; Yasaei, P.; Behranginia, A.; Zapol, P.; Klie, R. F.; Curtiss, L. A.; Salehi-Khojin, A. Cathode Based on Molybdenum Disulfide Nanoflakes for Lithium-Oxygen Batteries. ACS Nano 2016, 10, 2167-2175.

(26) Coleman, Jonathan N Lotya, M.; O’Neill, A.; Bergin, S. D.; King, P. J.; Khan, U.; Young, K.; Gaucher, A.; De, S.; Smith, R. J. Two-Dimensional Nanosheets Produced by Liquid Exfoliation of Layered Materials. Science 2011, 331, 568-571.

(27) Li, D. J.; Maiti, U. N.; Lim, J.; Choi, D. S.; Lee, W. J.; Oh, Y.; Lee, G. Y.; Kim, S. O. Molybdenum Sulfide/N-Doped CNT Forest Hybrid Catalysts for High-Performance Hydrogen Evolution Reaction. Nano Lett. 2014, 14, 1228-1233.

(28) Benck, J. D.; Chen, Z.; Kuritzky, L. Y.; Forman, A. J.; Jaramillo, T. F. Amorphous Molybdenum Sulfide Catalysts for Electrochemical Hydrogen Production: Insights into the Origin of Their Catalytic Activity. ACS Catal. 2012, 2, 1916-1923.

(29) Asadi, M.; Kumar, B.; Behranginia, A.; Rosen, B. A.; Baskin, A.; Repnin, N.; Pisasale, D.; Phillips, P.; Zhu, W.; Haasch, R.; Klie, R. F.; Kral, P.; Abiade, J.; Salehi-Khojin, A. Robust Carbon Dioxide Reduction on Molybdenum Disulphide Edges. Nat. Commun. 2014, 5, 4470.

(30) Reece, S. Y.; Hamel, J. A.; Sung, K.; Jarvi, T. D.; Esswein, A. J.; Pijpers, J. J. H.; Nocera, D. G. Wireless Solar Water Splitting Using Silicon-Based Semiconductors and Earth- 
Abundant Catalysts. Science 2011, 334, 645-648.

(31) Coridan, R. H.; Nielander, A. C.; Francis, S. A.; Mcdowell, M. T.; Dix, V.; Chatman, S. M.; Lewis, N. S. Methods for Comparing the Performance of Energy-Conversion Systems for Use in Solar Fuels and Solar Electricity Generation. Energy Environ. Sci. 2015, 8, 28862901.

(32) Singh, M. R.; Clark, E. L.; Bell, A. T. Thermodynamic and Achievable Efficiencies for Solar-Driven Electrochemical Reduction of Carbon Dioxide to Transportation Fuels. Proc. Natl. Acad. Sci. 2015, 112, E6111-E6118.

(33) Kresse, G.; Joubert, D. From Ultrasoft Pseudopotentials to the Projector AugmentedWave Method. Phys. Rev. B 1999, 59, 1758-1775.

(34) Perdew, J. P.; Burke, K.; Ernzerhof, M. Generalized Gradient Approximation Made Simple. Phys. Rev. Lett. 1996, 77, 3865-3868.

(35) Jain, A.; Ong, S. P.; Hautier, G.; Chen, W.; Richards, W. D.; Dacek, S.; Cholia, S.; Gunter, D.; Skinner, D.; Ceder, G.; Persson, A. K. Commentary: The Materials Project: A Materials Genome Approach to Accelerating Materials Innovation. APL Mater. 2013, 1, 011002.

(36) Ong, S. P.; Richards, W. D.; Jain, A.; Hautier, G.; Kocher, M.; Cholia, S.; Gunter, D.; Chevrier, V. L.; Persson, K. A.; Ceder, G. Python Materials Genomics (Pymatgen): A Robust, Open-Source Python Library for Materials Analysis. Comput. Mater. Sci. 2013, 68, 314-319. 